\title{
Mathematical Modelling of In-Vivo Dynamics of HIV Subject to the Influence of the CD8+ T-Cells
}

\author{
Purity M. Ngina*, Rachel Waema Mbogo, Livingstone S. Luboobi \\ Strathmore Institute of Mathematical Sciences, Strathmore University, Nairobi, Kenya \\ Email: *pngina@strathmore.edu
}

How to cite this paper: Ngina, P.M., Mbogo, R.W. and Luboobi, L.S. (2017) Mathematical Modelling of In-Vivo Dynamics of HIV Subject to the Influence of the $\mathrm{CD} 8^{+}$ T-Cells. Applied Mathematics, 8, 1153-1179. https://doi.org/10.4236/am.2017.88087

Received: June 19, 2017

Accepted: August 22, 2017

Published: August 25, 2017

Copyright @ 2017 by authors and Scientific Research Publishing Inc. This work is licensed under the Creative Commons Attribution International License (CC BY 4.0).

http://creativecommons.org/licenses/by/4.0/

(c) (i) Open Access

\begin{abstract}
There have been many mathematical models aimed at analysing the in-vivo dynamics of HIV. However, in most cases the attention has been on the interaction between the HIV virions and the $\mathrm{CD} 4^{+} \mathrm{T}$-cells. This paper brings in the intervention of the $\mathrm{CD}^{+} \mathrm{T}$-cells in seeking, destroying, and killing the infected $\mathrm{CD}_{4}^{+} \mathrm{T}$-cells during early stages of infection. The paper presents and analyses a five-component in-vivo model and applies the results in investigating the in-vivo dynamics of HIV in presence of the $\mathrm{CD} 8^{+} \mathrm{T}$-cells. We prove the positivity and the boundedness of the model solutions. In addition, we show that the solutions are biologically meaningful. Both the endemic and virions-free equilibria are determined and their stability investigated. In addition, the basic reproductive number is derived by the next generation matrix method. We prove that the virions-free equilibrium state is locally asymptotically stable if and only if $R_{0}<1$ and unstable otherwise. The results show that at acute infection the $\mathrm{CD} 8^{+} \mathrm{T}$-cells play a paramount role in reducing HIV viral replication. We also observe that the model exhibits backward and trans-critical bifurcation for some set of parameters for $R_{0}<1$. This is a clear indication that having $R_{0}<1$ is not sufficient condition for virions depletion.
\end{abstract}

\section{Keywords}

HIV, Endemic Equilibrium, Global Stability In-Vivo, Disease-Free Equilibrium, Basic Reproductive Number, Backward Bifurcation

\section{Introduction}

One of the most threatening retrovirus in the world is the Human Immunodeficiency Virus (HIV) that leads to Acquired Immunodeficiency Syndrome (AIDS). Unlike other viruses, HIV is encoded in ribonucleic acid (RNA) rather than 
deoxyribonucleic acid (DNA). HIV attacks the immune system, weakening it and eventually if not treated it makes the infected people highly vulnerable to various opportunistic infections. In absence of any HIV-management mechanism, infected people progresses to AIDS stage after 10 - 15 years [1]. HIV can be transmitted through various modes such as: Sharing sharp objects with infected people, having unprotected sex, transfusion using HIV-contaminated blood and mother to child transmission during either breast-feeding or via delivery.

Since the first case of HIV was reported in the early 1980's, HIV/AIDS has been associated to the deaths of more than 35 million people while over 36.9 million are living with the virus worldwide, making it one of the worst menace in the recorded history [2] [3] [4]. However, HIV remains a major cause of mortality in the world, having severe consequences mainly in sub-Saharan Africa, with a prevalence range of between $12 \%$ to $42 \%$ [3]. The greatest burden of HIV/AIDS lies with the poor communities, who also have the least access to antiretroviral therapy (ARTs) and interventions against HIV. Management, control and prevention of HIV require an integrated approach, which include, awareness/education and treatment with the best ARTs combinations. Lack of awareness/education, in access to early diagnosis and effective treatment has delayed the success of the global HIV programme in reducing new infection and severe HIV/AIDS related deaths. Therefore, there is need for new and more advanced interventions for HIV prevention, management and care.

According to [5], Kenya is among the six HIV high burden countries in the world having over 1.6 million individual living with the virus. Although Kenya had over 79,000 cases of new infection by 2015, she has however, made notable and outstanding strides in controlling and preventing HIV. For instance, the country has one of the world's highest HIV testing rates with about $72 \%$ of the total population having been tested at least once and 900,000 of the infected persons are on ARTs. However, not all efforts are reaching those who need these services. Consequently, concentrated epidemics are emerging among vulnerable groups such as youths, women, truck drivers, sex workers, prisoners, injecting-drug users, men who have sex with men, persons living with disabilities, discordant couples, orphan and vulnerable children. Therefore, control and prevention approaches should be tailored towards the aforementioned HIV special populations as part of wider efforts to control and curb the HIV/AIDS in Kenya. In addition, even with all the interventions, there are still a big number of Kenyans who do not know their HIV status. Therefore, it is important to increase HIV testing in order for people to be aware of their HIV status and be referred onto the best treatment, support and care according to the test outcomes. Kenyans economy and development has been affected severely by this menace. The Kenyan Government therefore, need to come up with sustainable methods of funding to improve existing HIV management efforts and to reduce the country's dependence on funding from donors and development partners.

In-vivo study for HIV dynamics have been done over the years, aimed at understanding the interaction mechanism of the body cells and the HIV virus. 
Such information has proved so valuable especially in the development of ARTs and in HIV management. In the recent years, mathematical models of various complexity level have been used to simulate and analyse such interactions unlike in the past where researches relied on clinical trials [6]. Consequently, many researchers [7] [8] [9] [10] in the field of epidiemiological modelling have embarked on the process of developing new models that could be used in the analysis of HIV dynamics. Many of the developed models describe and give insight on the various aspects that result from the interaction of HIV with healthy immune cells. The earliest mathematical models were based on the interaction between the $\mathrm{CD} 4^{+} \mathrm{T}$-cells and the HIV virions. These basic non-linear models were developed and used in the analysis of HIV dynamics and consequently, in estimating fundamental parameters that brought in new concepts of the disease processes and its progression [11]. With the aim of providing the most fundamental information on controlling the viral progression, most of these basic models include atleast three state variables, which include: the susceptible $\mathrm{CD} 4^{+}$ $\mathrm{T}$-cells, free HIV virions and the already infected $\mathrm{CD}^{+} \mathrm{T}$-cells. For instance, [12], formulated and analyzed an HIV model with three state variables, that is, the susceptible $\mathrm{CD} 4^{+} \mathrm{T}$-cells, the already infected $\mathrm{CD} 4^{+} \mathrm{T}$-cells and the free HIV virions. The model for instance, predicts adequately the disease progression from the early infection stage, asymptomatic stage, to full blown-AIDs and the viral load at the asymptomatic stage. However, great improvement on the model has been done and many other advanced models developed. [13] formulated a mathematical model representing a complete dynamic of HIV infection. The model aimed at analyzing the interaction between the $\mathrm{CD} 4^{+} \mathrm{T}$-cells, macrophage cells and the viral load. The results indicate that the $\mathrm{CD} 4^{+} \mathrm{T}$-cells play a very vital role as far as HIV virions replication is concerned. Similarly [6] analyzed a three component model for HIV. The model was aimed at analyzing the HIV dynamics during the initial stages of infection. The results showed that viral persistence was very high during initial stage of HIV infection.

Other researches have sought to study the role played by the killer T-cells in preventing virions replication in the body. In particular, [14] acknowledged the importance of the immune system in HIV infection dynamics by incorporating the $\mathrm{CD}^{+} \mathrm{T}$-cells in HIV dynamic model. The study developed a three-dimensional ordinary differential equations of the untreated model. The model showed the interaction between the non-infected $\mathrm{CD} 4^{+} \mathrm{T}$-cells, infected $\mathrm{CD} 4^{+} \mathrm{T}$-cells and the immune response. The model had a major shortcoming for its failure to incorporate the HIV virions. On other hand, [9], used a five-dimensional nonlinear ordinary differential equations (ODEs) model in showing the relationship between $\mathrm{CD}^{+} \mathrm{T}$-cells, virions, defense cells and ARTs. The results emphasized the importance of the $\mathrm{CD}^{+} \mathrm{T}$-cells in fighting the HIV virions during acute infection. It has been established that the disease become more endemic due to exponential virions replication and the failure of the ARTs to reach all the cells. Therefore, the focus on how to reduce virions replication by targeting the defense cell is inevitable and it will play a big role in ensuring that 
the endemicity of the infection is reduced.

In this paper, we shall mainly focus on HIV dynamics at acute HIV infection stage without any focus on the disease progression to AIDS stage which may come as a result of not using ARTs. The motivation behind this simple initial infection model is the fact that most of the new strategies for HIV management in Kenya such as the pre-exposure antiviral treatment and post-exposure antiviral treatment targets the HIV virions at the early stages of HIV-infection. For this study to be successful we develop a non-linear, five-dimensional deterministic model for in-vivo dynamics of HIV with inclusion of the CD8 ${ }^{+} \mathrm{T}$-cells.

\section{HIV Life Cycle}

HIV, like most viruses lacks the ability to replicate on its own and therefore, relies on a host for replication. Although, unlike all other viruses HIV is a retrovirus and hence carries the copies of its own RNA [2]. Once the virus gets in the body it mainly targets the $\mathrm{CD}^{+} \mathrm{T}$ cells by attaching itself on the membrane of the cell. After the infection of the cells by the virus, it is important to note that the symptoms do not show immediately until their level reduces to about 200 cells per $\mathrm{mm}^{3}$, and the viral load increases to 500 copies per $\mathrm{ml}$ [12]. The process of HIV replication is outlined in the following steps: First HIV virion joins the membrane of the $\mathrm{CD} 4^{+} \mathrm{T}$-cell. Then it fuses with the harbour cell and releases an enzyme known as reverse transcriptase. Reverse transcriptase enzyme transform the genome of the HIV virus to a double-stranded HIV DNA from a single-stranded HIV RNA. The transcription process ensures that integration of the HIV virion into the host DNA. Once HIV is integrated in the cells DNA, it starts to manufacture long chains of HIV protein using their DNA. The HIV proteins are the support system for more HIV virions. These long chains of HIV proteins (immature and non-infectious) assembles closer the membrane of the $\mathrm{CD}^{+}$cells and bud out. The immature virions then release an enzyme called the protease, which cut the long HIV proteins RNA into smaller individual proteins. As the smaller HIV proteins come together with copies of HIV's RNA genetic material, they form a new mature virus particle. Other cells can now be infected by the new HIV copies. This clearly shows that a single virion lead to the production of many other virions [15].

After infection the $\mathrm{CD}^{+}{ }^{+} \mathrm{T}$-cells sends a signal to the $\mathrm{CD} 8^{+} \mathrm{T}$-cells. The $\mathrm{CD} 8^{+}$ T-cells are aimed at destroying and killing the virions [9]. Unfortunately, despite immense effort from the mathematician in the field of mathematical modeling on HIV/AIDS analysis, the intervention of $\mathrm{CD}^{+} \mathrm{T}$-cells need to be analyzed further. Although researchers suggest that $\mathrm{CD} 8^{+} \mathrm{T}$-cells play a paramount role in host defense against the HIV virions nothing much has been done to show it especially during AIDS stage. One of the objectives of this paper is to present a realistic model that will analyze the importance of the $\mathrm{CD} 8^{+} \mathrm{T}$-cells in destroying the HIV virions. The $\mathrm{CD} 4^{+} \mathrm{T}$-cells play critical roles in controlling viral infections by prompting $\mathrm{CD} 8^{+} \mathrm{T}$-cells to eliminate the free HIV virions. The 


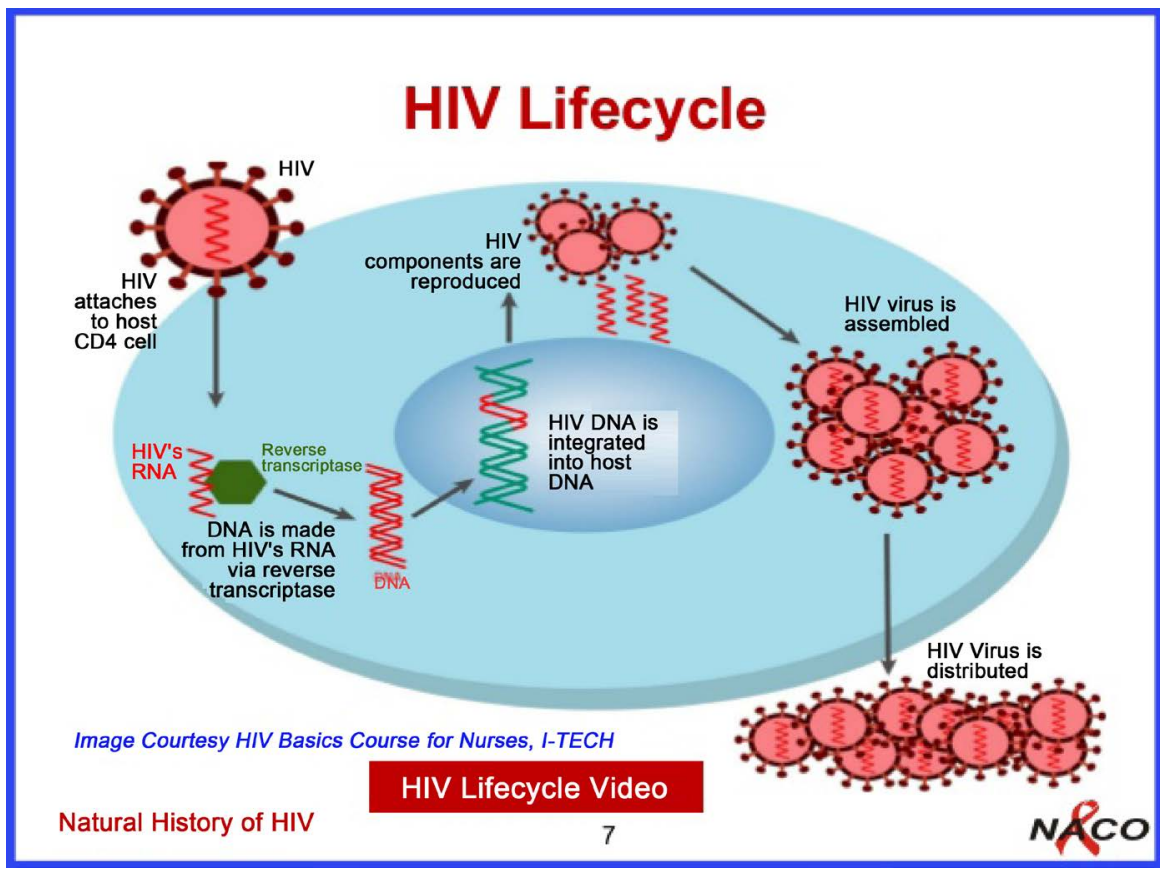

Source: HIV Basics Course for Nurses.

Figure 1. HIV Life Cycle.

HIV virus life cycle is presented in Figure 1.

\section{Mathematical Model for HIV Dynamics in-Vivo}

\subsection{Introduction}

An in-host HIV dynamics model with the inclusion of the immune cells is formulated. We show the model is positively invariant. The basic reproduction number expression is derived using the next generation matrix method. We also do the analyses on the stability of the steady points of the model.

\subsubsection{HIV Model Formulation}

We shall put into consideration a mathematical model for the in-vivo interaction of the HIV virions and the immune system cells. The model is classified into five compartments. The following are the variables used in the model (1) the healthy $\mathrm{CD} 4^{+} \mathrm{T}$-cells $(T)$, the infectious HIV virions $(V)$, the already infected $\mathrm{CD} 4^{+}$ T-cells $(I)$, the immune cells $(Z)$, that is, $\mathrm{CD}^{+}$T-cells and the activated immune cells $\left(Z_{a}\right)$.

The healthy $\mathrm{CD} 4^{+} \mathrm{T}$-cells are recruited at a constant rate $\lambda_{T}$ from the bone marrow and die naturally at a constant rate $\mu_{T}$. The healthy CD4 $4^{+} \mathrm{T}$-cells are as a result of the interaction between the uninfected $\mathrm{CD} 4^{+} \mathrm{T}$-cells and the virus at a rate $\chi$. They die naturally at a rate $\mu_{I}$, they are also eliminated by the activated $\mathrm{CD} 4^{+} \mathrm{T}$-cells at the rate $\alpha$. In addition, the infected healthy $\mathrm{CD} 4^{+} \mathrm{T}$-cells produces an average of $\epsilon_{V}$ viral particles. The new mature virions produced will infect other $\mathrm{CD} 4^{+} \mathrm{T}$-cells. The HIV virions population increases due to the budding of the infected $\mathrm{CD} 4^{+} \mathrm{T}$-cells at a rate $\epsilon_{V}$ and die at the rate $\mu_{V}$. The 
$\mathrm{CD}^{+} \mathrm{T}$-cells, are generated from the thymus at a constant rate $\lambda_{z}$, and die naturally at a constant rate $\mu_{z}$. Due to the presence of the HIV virions the $\mathrm{CD}^{+} \mathrm{T}$-cells become activated at the rate $\beta$. The activated $\mathrm{CD} 8^{+} \mathrm{T}$-cells are produced from the $\mathrm{CD} 8^{+} \mathrm{T}$-cells the in the presence of the HIV virions, at rate $\beta$ and die naturally at rate $\mu_{Z_{a}}$. The interaction description can be summarized in Table 1 and Table 2 which represent the Variables and parameters respectively.

We present the model diagram in Figure 2. The diagram represent visually a mechanisms which govern the system of differential equations for system (1).

From Figure 2, we derive the following system of initial value non-linear differential equation for the in-vivo HIV dynamics model;

$$
\begin{aligned}
& \frac{\mathrm{d} T}{\mathrm{~d} t}=\lambda_{T}-\mu_{T} T-\chi T V, \\
& \frac{\mathrm{d} I}{\mathrm{~d} t}=\chi T V-\mu_{I} I-\alpha I Z_{a}, \\
& \frac{\mathrm{d} V}{\mathrm{~d} t}=\epsilon_{V} \mu_{I} I-\mu_{V} V, \\
& \frac{\mathrm{d} Z}{\mathrm{~d} t}=\lambda_{\mathrm{Z}}-\mu_{\mathrm{Z}} \mathrm{Z}-\beta Z I, \\
& \frac{\mathrm{d} Z_{a}}{\mathrm{~d} t}=\beta Z I-\mu_{Z_{a}} Z_{a}
\end{aligned}
$$

Table 1. Variables for HIV in-vivo model.

\begin{tabular}{cl}
\hline Variable & \multicolumn{1}{c}{ Description } \\
\hline$T(t)$ & The concentration of the susceptible $\mathrm{CD} 4^{+} \mathrm{T}$ cells at any time $t$ \\
$I(t)$ & The concentration of the infected $\mathrm{CD} 4^{+} \mathrm{T}$ cells at any time $t$ \\
$V(t)$ & The concentration of infectious HIV virions at any time $t$ \\
$Z(t)$ & The concentration of the $\mathrm{CD} 8^{+} \mathrm{T}$-cells at any time $t$ \\
$Z_{a}(t)$ & The population of the activated $\mathrm{CD} 8^{+} \mathrm{T}$-cells at any time $t$ \\
\hline
\end{tabular}

Table 2. Parameters for HIV in-vivo model.

\begin{tabular}{cl}
\hline Parameter & \multicolumn{1}{c}{ Description } \\
\hline$\lambda_{T}$ & The recruitment rate of the susceptible $\mathrm{CD} 4^{+} \mathrm{T}$-cells per unit time. \\
$\mu_{T}$ & The decay rate of the susceptible $\mathrm{CD} 4^{+} \mathrm{T}$-cells. \\
$\chi$ & The infection rate of the $\mathrm{CD} 4^{+} \mathrm{T}$-cells by the virus. \\
$\mu_{I}$ & The natural death rate of the infected $\mathrm{CD} 4^{+} \mathrm{T}$-cells. \\
$\epsilon_{\mathrm{V}}$ & The HIV virions generation rate from the infected $\mathrm{CD} 4^{+} \mathrm{T}$-cells. \\
$\mu_{V}$ & The death rate of the infectious virus. \\
$\alpha$ & The rate at which the infected cells are eliminated by the activated $\mathrm{CD} 8^{+} \mathrm{T}$-cells. \\
$\lambda_{z}$ & The recruitment rate of the CD8 ${ }^{+} \mathrm{T}$-cells per unit time. \\
$\mu_{Z}$ & The death rate of the $\mathrm{CD} 8^{+} \mathrm{T}$-cells. \\
$\beta$ & The activation rate of the $\mathrm{CD} 8^{+} \mathrm{T}$-cells due to the presence the infected $\mathrm{CD} 4^{+} \mathrm{T}$-cells. \\
$\mu_{z_{a}}$ & The decay rate at of the activated defence cells decay per unit time. \\
\hline
\end{tabular}




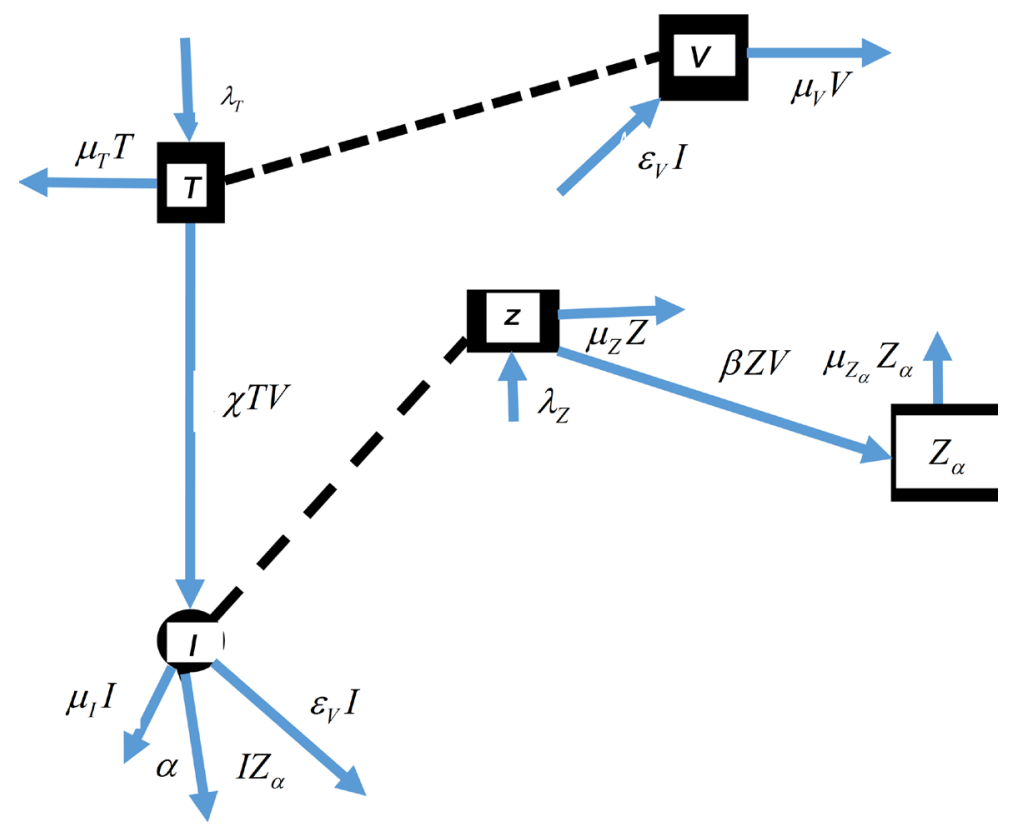

Figure 2. A compartmental representation of the in-vivo HIV Dynamics.

\section{Basic Properties of the Model}

Before commencing the steady-states analysis of the model (1), it is important to look at some properties to ensure existence of biologically meaningful solutions.

\subsection{Boundedness and the Positivity of the Model Solutions}

Before we analyze the model (1) it is paramount to prove that the key variables are non-negative implying that the model solutions will be positive for all $t>0$ and must be bounded for all $t>0$ in an invariant region. Invariant region is the area in which the model is well posed mathematically and has biological meaning.

Theorem 1. Let the initial values of the state variables be $T(0) \geq 0, V(0) \geq 0$, $I(0) \geq 0, Z(0) \geq 0, Z_{a}(0) \geq 0$. Then show that, for every $t>0$ the solution set $\Gamma=\{T(t), V(t), I(t), Z(t), Z a(t)\}$ of the model (1) is non-negative and $\Gamma$ is the invariant region.

Proof. Taking the first part of Equation (1) we have,

$$
\begin{aligned}
& \frac{\mathrm{d} T(t)}{\mathrm{d} t} \geq-\mu_{T} T-\chi T V \\
& T(t) \geq T(0) \mathrm{e}^{J-\left(\mu_{T}+\chi V\right) \mathrm{d} t},
\end{aligned}
$$

Hence $T$ is non-negative for all $t>0$.

Similarly for the infected $\mathrm{CD} 4^{+} \mathrm{T}$-cells we have,

$$
\frac{\mathrm{d} I}{\mathrm{~d} t}=\chi T V-\mu_{I} I-\alpha I Z_{a} \geq-\left(\mu_{I}-\alpha Z_{a}\right) I
$$

By integration and separation of variables Equation (3) gives,

$$
I \geq I(0) \mathrm{e}^{\int-\left(\mu_{I}+\alpha Z_{a}\right) \mathrm{d} t}
$$

Hence I is non-negative for all $t>0$. 
Similarly for the HIV virions we have,

$$
\frac{\mathrm{d} V}{\mathrm{~d} t}=\epsilon_{V} \mu_{I} I-\mu_{V} V \geq-\mu_{V}
$$

By integration and separation variables Equation (3) gives,

$$
V \geq V(0) \mathrm{e}^{\int-\left(\mu_{V}\right) \mathrm{d} t}
$$

Hence $V$ is non-negative for all $t>0$.

For the $\mathrm{CD}^{+}$, part four of model (1) gives

$$
\begin{aligned}
& \frac{\mathrm{d} Z}{\mathrm{~d} t}=\lambda_{\mathrm{Z}}-\mu_{\mathrm{Z}} Z-\beta Z I \geq-\left(\mu_{\mathrm{Z}}+\beta I\right) Z \\
& \frac{\mathrm{d} Z}{\mathrm{~d} t} \geq-\left(\mu_{\mathrm{Z}}+\beta I\right) Z
\end{aligned}
$$

We separate variables and integrate both sides with respect to the corresponding variables as follow,

$$
Z \geq Z(0) \mathrm{e}^{\int-\left(\mu_{Z}+\beta I\right) \mathrm{d} t}
$$

Hence $\mathrm{Z}$ is non-negative for all $t>0$.

Finally for the activated immune cells we have;

$$
\begin{aligned}
& \frac{\mathrm{d} Z_{a}}{\mathrm{~d} t}=\beta Z I-\mu_{\mathrm{za}} Z_{a} \geq-\left(\mu_{\mathrm{za}} Z_{a}\right) \\
& \frac{\mathrm{d} Z_{a}}{\mathrm{~d} t} \geq-\left(\mu_{\mathrm{za}} Z_{a}\right)
\end{aligned}
$$

By integration and separation of variables we get;

$$
Z_{a} \geq Z_{a}(0) \mathrm{e}^{\int-\left(\mu_{z a}\right) \mathrm{d} t}
$$

Hence $Z_{a}$ is non-negative for all $t>0$.

\subsection{Invariant Region}

Notably, all the state variables of system (1) have been proved to be non-negative. In addition, parameters of model (1) monitors cell population, hence they are also non-negative for all, $t>0$. Consequently the model (1) analysis is done in the region $\Gamma$ that is biologically meaningful.

Theorem 2. Let $T(t) \geq 0, V(t) \geq 0, I(t) \geq 0, Z(t) \geq 0, Z_{a}(t) \geq 0$. Then the solutions of $T(t), V(t), I(t), Z(t), Z_{a}(t)$ are bounded and the region $\Gamma$ is positively invariant for all $t \geq 0$.

$\Gamma=\left\{\left(T(t), I(t), V(t), Z(t), Z_{a}(t)\right) \in \mathbb{R}^{5}, T+I \leq \frac{\lambda_{T}}{\mu_{T}}, Z+Z_{a} \leq \frac{\lambda_{Z}}{\mu_{Z}}, V \leq \frac{\varepsilon_{V} \mu_{I} \lambda_{T}}{\mu_{T} \mu_{V}}+V_{0}\right\}(10)$

Proof. The total population of the $\mathrm{CD}^{+}$T-cells, $T+I=N_{4}(t)$, is clearly non-constant value. Hence the evolution equation representing the change in the population of the $\mathrm{CD} 4^{+} \mathrm{T}$-cells is;

$$
\begin{aligned}
& \frac{\mathrm{d} N_{4}(t)}{\mathrm{d} t}=\lambda_{T}-\mu_{T} T-\mu_{I} I-\alpha \mathrm{IZ}_{a}, \\
& \frac{\mathrm{d} N_{4}(t)}{\mathrm{d} t} \leq \lambda_{T}-\mu_{T} N_{4}(t)
\end{aligned}
$$


By separation of variables method for solving differential inequality, Equation (11) becomes;

$$
\begin{aligned}
& \frac{\mathrm{d} N_{4}(t)}{\lambda_{T}-\mu_{T} N_{4}(t)} \leq \mathrm{d} t, \\
& \ln \left(\lambda_{T}-\mu_{T} N_{4}(t)\right)^{-} \frac{1}{\mu_{T}} \geq \ln C+t
\end{aligned}
$$

Thus, Equation (12) reduces to;

$$
\ln \left(\lambda_{T}-\mu_{T} N_{4}(t)\right)^{-\frac{1}{\mu_{T}}} \geq C \mathrm{e}^{\mu_{T} t}
$$

But

$$
C=\lambda_{T}-\mu_{T} N_{0}
$$

Therefore, Equation (12) becomes;

$$
N_{4}(t) \leq \frac{\lambda_{T}}{\mu_{T}}-\frac{\left(\lambda_{T}-\mu_{T} N_{0}\right) \mathrm{e}^{-\mu_{T} t}}{\mu_{T}}
$$

Thus at any time $t>0$ we have;

$$
N_{4}(t) \leq \max \left\{N_{0}, \frac{\lambda_{T}}{\mu_{T}}\right\}
$$

Hence, all feasible solutions set for the $\mathrm{CD}^{+}{ }^{+} \mathrm{T}$-cells of the model (1) enters the region:

$$
\Gamma_{T}=\left\{(T(t), I(t)) \in \mathbb{R}^{2}, N_{4} \leq \max \left\{N_{0}, \frac{\lambda_{T}}{\mu_{T}}\right\}\right\}
$$

Similarly the total number of the $\mathrm{CD}^{+} \mathrm{T}$-cells, $Z+Z_{a}=N_{8}(t)$, at disease free equilibrium are given by;

$$
\frac{\mathrm{d} N_{8}(t)}{\mathrm{d} t}=\lambda_{\mathrm{Z}}-\mu_{\mathrm{Z}} N_{8}(t)
$$

By separation of variables method for solving differential inequality Equation (18) becomes;

$$
\frac{\mathrm{d} N_{8}(t)}{\lambda_{z}-\mu_{z} N_{8}(t)} \leq \mathrm{d} t
$$

Integrating Equation (19) we have

$$
N_{8}(t) \leq \frac{\lambda_{Z}}{\mu_{z}}-\frac{\left(\lambda_{z}-\mu_{Z} N_{0} c\right) \mathrm{e}^{-\mu_{Z} t}}{\mu_{z}}
$$

Thus at any time $t>0$ we have;

$$
N_{8}(t) \leq \max \left\{N_{0} c, \frac{\lambda_{Z}}{\mu_{Z}}\right\}
$$

Hence, all feasible solutions set for the $\mathrm{CD}^{+}{ }^{+} \mathrm{T}$-cells of the model (1) enters the region; 


$$
\Gamma_{Z}=\left\{\left(Z(t), Z_{a}(t)\right) \in \mathbb{R}^{2}, N_{8}(t) \leq \max \left\{N_{0} c, \frac{\lambda_{Z}}{\mu_{Z}}\right\}\right\}
$$

Considering the $V$ population of the model (1) we have'

$$
\frac{\mathrm{d} V(t)}{\mathrm{d} t} \leq \varepsilon_{V} \mu_{I} \frac{\lambda_{T}}{\mu_{T}}-\mu_{V} V \text {, since } I \leq \frac{\lambda_{T}}{\mu_{T}}
$$

Integration gives

$$
\begin{aligned}
& \frac{\mathrm{d} V}{\mathrm{~d} t}+\mu_{V} V \leq \varepsilon_{V} \mu_{I} \frac{\lambda_{T}}{\mu_{T}} \\
& V \leq \frac{\varepsilon_{V} \mu_{I} \lambda_{T}}{\mu_{T} \mu_{V}}+V_{0}
\end{aligned}
$$

Hence $V$ is bounded. Consequently the feasible solution for the model (1) is;

$$
\Gamma=\left\{\left(T(t), V(t), I(t), Z(t), Z_{a}(t)\right) \in \mathbb{R}^{5}, T+I \leq \frac{\lambda_{T}}{\mu_{T}}, Z+Z_{a} \leq \frac{\lambda_{Z}}{\mu_{Z}}, V \leq \frac{\varepsilon_{V} \mu_{I} \lambda_{T}}{\mu_{T} \mu_{V}}+V_{0}\right\}
$$

All the state variables are positive and bounded. Consequently, from Equation (25), $\Gamma$ is positively invariant of model (1). Hence, it is possible to study the dynamics of the HIV model (1) in $\Gamma$.

With theorem 2 we conclude that the model is valid and will remain so during the whole course of study if and only if the initial data are biologically meaningful. In addition it is evident that with time the number of virions will reduce to nondetectable level.

Remark 1. Suppose $T(0), I(0), V(0), Z(0), Z_{a}(0)>0$ be given. Then there exist a differentiable continuous function $T, I, V, Z, Z_{a}:\left[0, T_{f}\right] R$ such that $\left(T, I, V, Z, Z_{a}\right)$ is bounded and $\left(T, I, V, Z, Z_{a}\right)(0)=\left(T(0), I(0), V(0), Z(0), Z_{a}(0)\right)$.

Therefore, the model solutions will always be positive if the initial values for the state variables are non-negative for all $t>0$ in the closed interval $\left[0, T_{f}\right]$.

\section{Equilibria and Reproductive Number}

For us to fully understand the dynamics of the five component HIV model we study its stability. In this model there exist two critical points. The critical points represent the case before the virions get to the body, that is virions-free equilibrium point that is, $V=I=Z_{a}=0$, and when the virus persist in the body, that is, $V \neq 0, I \neq 0$ and $Z_{a} \neq 0$.

Before infection by HIV virions, the model as represented by Equation (1), has a unique feasible HIV-free steady state solution to be referred to as the virions-free equilibrium (VFE). The virions-free equilibrium of the model (1) is given by:

$$
E_{0}\left(T, I, V, Z, Z_{a}\right)=\left[\frac{\lambda_{T}}{\mu_{T}}, 0,0, \frac{\lambda_{Z}}{\mu_{Z}}, 0\right]
$$

\subsection{Basic Reproductive Number}

Researchers in the field of in-vivo HIV modelling aims at finding the optimal 
conditions that determine the spread of the HIV virions in the susceptible CD4 $4^{+}$ T-cells. In order to do this, researchers consider the basic reproductive number $\left(R_{0}\right)$. According to [16], the basic reproductive number represent the number of secondary infection that result from single infected T-cell. $R_{0}$ measures the potential of HIV spread in the host and probably attacking a large number of the T-cells. The $R_{0}$ obtained for the virions-free equilibrium by the next generation matrix guarantee local stability of the model (1). $R_{0}$ is used in stability analysis of the critical points. If $R_{0}<1$ the virions-free equilibrium is locally asymptotically stable and if $R_{0}>1$ it is said to be unstable. Notably, a large value of $R_{0}$ indicates disease epidemic. Consequently, in order to control viral replication it is important to ensure that $0<R_{0}<1$.

\section{Computation of $\boldsymbol{R}_{\mathbf{0}}$}

In this paper we shall adopt the next generation matrix method for the derivation of $R_{0}$ [16]. Mathematically, $R_{0}$ is given by $R_{0}=\rho\left(F V^{-1}\right)$ where $\rho$ is the spectral radius of the next generation matrix [17] and $F$ is the matrix of the infections while $V$ is the transfer of individuals out of compartment [18]. The expression of $R_{0}$ is the dominant eigenvalue of the next generation matrix. In model (1) we have two infection classes, therefore, the matrix of new infection at the virions-free equilibrium is given by;

$$
F=\left[\begin{array}{cc}
0 & \frac{\chi \lambda_{T}}{\mu_{T}} \\
0 & 0
\end{array}\right]
$$

The matrix that represent the transfer between compartments at the disease-free equilibrium given respectively by,

$$
V=\left[\begin{array}{cc}
\mu_{I} & 0 \\
-\varepsilon_{V} \mu_{I} & \mu_{V}
\end{array}\right]
$$

The inverse of $V$ is given by;

$$
V^{-1}=\left[\begin{array}{cc}
\frac{1}{\mu_{I}} & 0 \\
\frac{\varepsilon_{V}}{\mu_{V}} & \frac{1}{\mu_{V}}
\end{array}\right]
$$

The next generation matrix $F V^{-1}$ is given by;

$$
F V^{-1}=\left[\begin{array}{cc}
\frac{\chi \varepsilon_{V} \lambda_{T}}{\mu_{V} \mu_{T}} & \frac{\chi \lambda_{T}}{\mu_{T} \mu_{V}} \\
0 & 0
\end{array}\right]
$$

The eigenvalues of the matrix above are; $\frac{\chi \varepsilon_{V} \lambda_{T}}{\mu_{V} \mu_{T}}$ and 0 , therefore, the reproductive number (which is the largest eigenvalue) is given by;

$$
\mathcal{R}_{0}=\frac{\chi \varepsilon_{V} \lambda_{T}}{\mu_{V} \mu_{T}}
$$




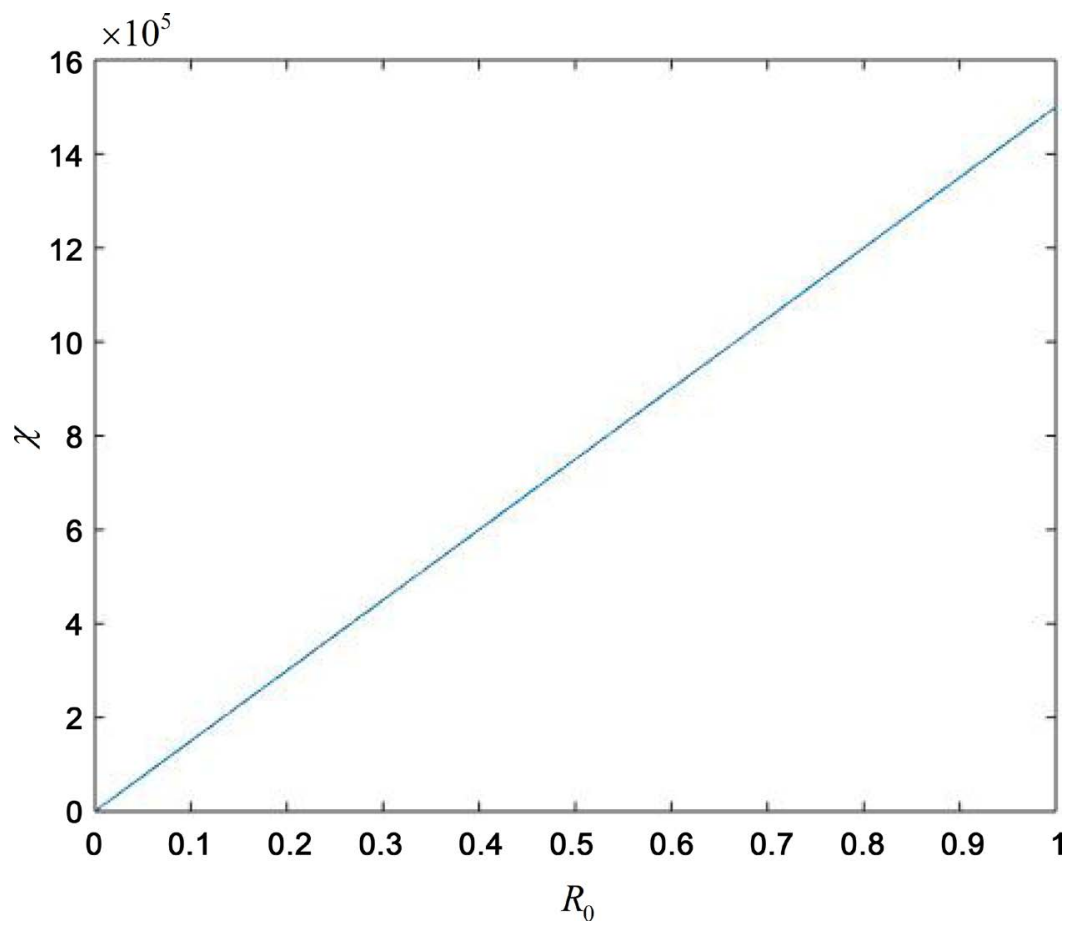

Figure 3. Basic Reproductive number increases with the infection rate.

Figure 3 illustrates how $R_{0}$ is affected by the change of $\chi$.

Increasing the infection rate would lead to a rise in the number of secondary infection this is clearly depicted from the reproductive number given in Equation (31). The only way of reducing this is by introducing ARTs that target the HIV lifecycle at the entry level of the HIV virions to the CD4 $4^{+} \mathrm{T}$-cells, that is, during fusion stage and hence the recommended drugs are the Fusion Inhibitors. Similarly, increasing the rate at which free HIV virions are generated from the infected cells would lead to an increase in the reproductive number. This means that it is paramount to bring in treatment at the budding level or to introduce ARTs drugs that would help in ensuring that the HIV virions generated from the infected $\mathrm{CD}^{+}{ }^{+} \mathrm{T}$-cells are defective and non-infectious. The ARTs that can play that role are the protease inhibitors. The protease inhibitors (PIs) inhibits the release of the viral protease enzyme that ensures the maturity of HIV virions upon budding from the host membrane. Consequently, the virions produced by the infected cells after the introduction of PIs are defective and non-infectious [19]. Conversely, if the rate at which the virus dies increases the rate of secondary infection would be at the minimum level. The HIV virions can die naturally or triggered by the $\mathrm{CD}^{+} \mathrm{T}$-cells. According to [9], the $\mathrm{CD} 8^{+} \mathrm{T}$-cells seek, destroy, and kill the cells infected by the HIV virions. This means that if the $\mathrm{CD}^{+} \mathrm{T}$-cells are able to fight the virions by killing the infected $\mathrm{CD}^{+} \mathrm{T}$-cells the number of secondary infection would reduce and eventually the virions maybe eliminated from the body. This shows that during the initial HIV infection stage $\mathrm{CD}^{+} \mathrm{T}$-cells are very important as far as fighting and reducing HIV virions replication is concerned. The most fundamental thing would for 
researcher to establish what happens to $\mathrm{CD} 8^{+} \mathrm{T}$-cells at the chronic level. Do they still fight the virus? Or probably are the $\mathrm{CD} 4^{+} \mathrm{T}$-cells so worn out that they are not able to alert the $\mathrm{CD} 8^{+} \mathrm{T}$-cells?

\subsection{Local Stability of the Virions-Free Equilibrium (VFE)}

Theorem 3. The virions-free equilibrium $E_{0}$ of the model (1) is locally asymptotically stable if $R_{0}<1$ and unstable if $R_{0}>1$

Proof. In this study we have a non-linear differential equations model hence we shall use linearization method by [20] to study and prove the local stability of the virions-free equilibrium. The Jacobian matrix of the DFE for the model (1) is given by:

$$
J=\left|\begin{array}{ccccc}
-\mu_{T} & 0 & -\chi T & 0 & 0 \\
0 & -\mu_{I} & \chi T & 0 & 0 \\
0 & \varepsilon_{V} \mu_{I} & -\mu_{V} & 0 & 0 \\
0 & -\beta Z & 0 & -\mu_{Z} & 0 \\
0 & \beta Z & 0 & 0 & -\mu_{Z a}
\end{array}\right|
$$

Substituting Equation (26) into Equation (32) we have;

$$
J\left(E_{0}\right)=\left|\begin{array}{ccccc}
-\mu_{T} & 0 & -\chi \frac{\lambda_{T}}{\mu_{T}} & 0 & 0 \\
0 & -\mu_{I} & \chi \frac{\lambda_{T}}{\mu_{T}} & 0 & 0 \\
0 & \varepsilon_{V} \mu_{I} & -\mu_{V} & 0 & 0 \\
0 & -\beta \frac{\lambda_{Z}}{\mu_{Z}} & 0 & -\mu_{Z} & 0 \\
0 & \beta \frac{\lambda_{Z}}{\mu_{Z}} & 0 & 0 & -\mu_{Z a}
\end{array}\right|
$$

The characteristic equation in $\Lambda$ for Equation (33) is given by

$$
\Lambda^{5}-b_{4} \Lambda^{4}-b_{3} \Lambda^{3}-b_{2} \Lambda^{2}-b_{1} \Lambda+b_{0}=0
$$

where,

$$
\begin{aligned}
b_{4}= & -\mu_{Z a}-\mu_{Z}+\mu_{V}-\mu_{I}+\mu_{T} \\
b_{3}= & \chi \frac{\lambda_{T}}{\mu_{T}} \varepsilon_{V} \mu_{I}-\lambda_{T} \mu_{Z a}-\lambda_{T} \mu_{Z}-\lambda_{T} \mu_{I}-\lambda_{T} \mu_{V}-\mu_{Z a} \mu_{Z} \\
& -\mu_{Z a} \mu_{I}-\mu_{Z a} \mu_{V}-\mu_{Z} \mu_{I}-\mu_{Z} \mu_{V}-\mu_{I} \mu_{V} \\
b_{2}= & \lambda_{T} \chi \frac{\lambda_{T}}{\mu_{T}} \varepsilon_{V} \mu_{I}+\chi \frac{\lambda_{T}}{\mu_{T}} \mu_{Z a} \varepsilon_{V} \mu_{I}+\mu_{Z} \varepsilon_{V} \mu_{I} \chi \frac{\lambda_{T}}{\mu_{T}}-\lambda_{T} \mu_{Z a} \mu_{Z} \\
& -\lambda_{T} \mu_{Z a} \mu_{I}-\lambda_{T} \mu_{Z a} \mu_{V}-\lambda_{T} \mu_{Z} \mu_{I}-\lambda_{T} \mu_{Z} \mu_{V}-\lambda_{T} \mu_{I} \mu_{V} \\
& -\mu_{Z a} \mu_{Z} \mu_{I}-\mu_{Z a} \mu_{Z} \mu_{V}-\mu_{Z a} \mu_{I} \mu_{V}-\mu_{Z} \mu_{I} \mu_{V} \\
b_{1}= & \lambda_{T} \mu_{Z a} \varepsilon_{V} \mu_{I} \chi \frac{\lambda_{T}}{\mu_{T}}+\lambda_{T} \mu_{Z} \varepsilon_{V} \mu_{I} \chi \frac{\lambda_{T}}{\mu_{T}}+T \mu_{Z a} \mu_{Z} \varepsilon_{V} \mu_{I} \chi \frac{\lambda_{T}}{\mu_{T}}+\lambda_{T} \mu_{Z a} \mu_{Z} \mu_{I} \\
& -\lambda_{T} \mu_{Z a} \mu_{Z} \mu_{V}-\lambda_{T} \mu_{Z a} \mu_{I} \mu_{V}-\lambda_{T} \mu_{Z} \mu_{I} \mu_{V}-\mu_{Z a} \mu_{Z} \mu_{I} \mu_{V}
\end{aligned}
$$




$$
b_{0}=\mu_{\text {Za }} \mu_{\mathrm{Z}} \mu_{I} \lambda_{T}\left(\varepsilon_{V} \frac{\lambda_{T}}{\mu_{V}}-\mu_{V}\right)
$$

The eigenvalues for the Jacobian matrix are given by; $\Lambda_{1}=-\mu_{T}, \Lambda_{2}=-\mu_{Z}$, $\Lambda_{3}=-\mu_{\text {Za }}$,

$$
\begin{aligned}
& \Lambda_{4}=\frac{-\mu_{I} \mu_{T}-\mu_{V} \mu_{T}+\sqrt{4 \chi \lambda_{T} \mu_{I} \mu_{T} \varepsilon_{V}+\mu_{I}^{2} \mu_{T}^{2}-2 \mu_{I} \mu_{T}^{2} \mu_{V}+\mu_{T}^{2} \mu_{V}^{2}}}{2 \mu_{T}}, \\
& \Lambda_{5}=-\frac{\mu_{I} \mu_{T}+\mu_{V} \mu_{T}+\sqrt{4 \chi \lambda_{T} \mu_{I} \mu_{T} \varepsilon_{V}+\mu_{I}^{2} \mu_{T}^{2}-2 \mu_{I} \mu_{T}^{2} \mu_{V}+\mu_{T}^{2} \mu_{V}^{2}}}{2 \mu_{T}}
\end{aligned}
$$

It is evident that $\Lambda_{1}, \Lambda_{2}, \Lambda_{3}$ and $\Lambda_{5}$. However we need to determine the conditions that would guarantee that $\Lambda_{4}$ is also negative, since for local stability all the eigenvalues must be negative.

Suppose $\Lambda_{4}<0$, we have:

$$
\begin{aligned}
& \frac{-\mu_{I} \mu_{T}-\mu_{V} \mu_{T}+\sqrt{4 \chi \lambda_{T} \mu_{I} \mu_{T} \varepsilon_{V}+\mu_{I}^{2} \mu_{T}^{2}-2 \mu_{I} \mu_{T}^{2} \mu_{V}+\mu_{T}^{2} \mu_{V}^{2}}}{2 \mu_{T}}<0, \\
& \left(\mu_{I} \mu_{T}+\mu_{V} \mu_{T}\right)^{2}>4 \chi \lambda_{T} \mu_{I} \mu_{T} \varepsilon_{V}+\mu_{I}^{2} \mu_{T}^{2}-2 \mu_{I} \mu_{T}^{2} \mu_{V}+\mu_{T}^{2} \mu_{V}^{2}, \\
& \mu_{V} \mu_{T}>\chi \lambda_{T} \varepsilon_{V}
\end{aligned}
$$

Thus, from Equation (35) we have;

$$
\frac{\chi \lambda_{T} \varepsilon_{V}}{\mu_{V} \mu_{T}}<1
$$

From (36) we deduce that $R_{0}=\frac{\chi \lambda_{T} \varepsilon_{V}}{\mu_{V} \mu_{T}}<1$. Thus, the virions-free equilibrium is locally asymptotically stable.

\subsection{The Endemic Equilibrium}

To analyze the endemic equilibrium, this study adopt the assumption made by [14] that the free virus spread of infection and there is no cell-to-cell transfer of the HIV virions. The endemic equilibrium $E_{1}$ exist when, $T(t)>0, I(t)>0$, $V(t)>0, Z(t)>0, Z_{a}(t)>0$. An endemic equilibrium $E_{1}=\left(T^{*}, I^{*}, V^{*}, Z^{*}, Z_{a}^{*}\right)$, satisfies;

$$
\begin{aligned}
& \lambda_{T}^{*}-\mu_{T} T^{*}-\chi T^{*} V^{*}=0, \\
& \chi T^{*} V^{*}-\mu_{I} I^{*}-\alpha I^{*} Z_{a}^{*}=0, \\
& \epsilon_{V} \mu_{I} I^{*}-\mu_{V} V^{*}=0, \\
& \lambda_{Z}-\mu_{Z} Z^{*}-\beta Z^{*} I^{*}=0, \\
& \beta Z^{*} I^{*}-\mu_{z a} Z_{a}^{*}=0
\end{aligned}
$$

Hence, the endemic equilibria of the model (1) correspond to the non-negative solutions of the Equation (37). Therefore, we solve the system (37) in terms of $Z_{a}^{*}$ and obtain the endemic equilibrium as; 


$$
\begin{aligned}
T^{*} & =\frac{\lambda_{T} \mu_{v} \beta\left(\lambda_{Z}-Z_{a}^{*} \mu_{z a}\right)}{\mu_{T} \mu_{v} \beta\left(\lambda_{Z}-Z_{a}^{*} \mu_{Z a}\right)+Z_{a}^{*} \epsilon_{v} \mu_{z} \chi \mu_{Z a} \mu_{T}}, \\
I^{*} & =\frac{Z_{a}^{*} \mu_{z a} \mu_{Z}}{\beta\left(\lambda_{Z}-Z_{a}^{*} \mu_{Z a}\right)}, \\
V^{*} & =\frac{\epsilon_{V} \mu_{Z} \mu_{\text {Za }} \mu_{I} Z_{a}^{*}}{\beta \mu_{v}\left(\lambda_{Z}-Z_{a}^{*} \mu_{Z a}\right)}, \\
Z^{*} & =\frac{\lambda_{Z}-Z_{a}^{*} \mu_{z a}}{\mu_{Z}} .
\end{aligned}
$$

We then obtain the following cubic polynomial that describes the existence of the possible equilibria.

$$
p\left(Z_{a}^{*}\right)=Z_{a}^{*}\left(\Phi_{2} Z_{a}^{* 2}+\Phi_{1} Z_{a}^{*}+\Phi_{0}\right)=0
$$

where,

$$
\left.\begin{array}{l}
\Phi_{2}=-4 \beta \mu_{\text {Za }} \mu_{Z}\left(\mu_{\text {Za }} \mu_{I}+\alpha \lambda_{Z}\right), \\
\Phi_{1}=4 \mu_{\text {Za }} \mu_{Z} \mu_{T}\left[-R_{0} \mu_{I} \mu_{\text {Za }}\left(\mu_{I} \mu_{Z}-\beta \lambda_{T}\right)-\lambda_{T} \beta\left(\mu_{I} \mu_{\text {Za }}+\alpha \lambda_{Z}\right)\right], \\
\Phi_{0}=4 R_{0} \mu_{\text {Za }}^{2} \mu_{Z}^{2} \mu_{T}^{2} \mu_{V}^{2}\left(R_{0}-1\right) .
\end{array}\right\}
$$

We re-write Equation (40) to ensure that $\Phi_{2}>0$ as;

$$
\left.\begin{array}{l}
\Phi_{2}=4 \beta \mu_{\text {Za }} \mu_{Z}\left(\mu_{\text {Za }} \mu_{I}+\alpha \lambda_{Z}\right), \\
\Phi_{1}=-4 \mu_{\text {Za }} \mu_{Z} \mu_{T}\left[R_{0} \mu_{I} \mu_{\text {Za }}\left(\mu_{I} \mu_{Z}-\beta \lambda_{T}\right)+\lambda_{T} \beta\left(\mu_{I} \mu_{\text {Za }}+\alpha \lambda_{Z}\right)\right], \\
\Phi_{0}=4 R_{0} \mu_{\text {Za }}^{2} \mu_{Z}^{2} \mu_{T}^{2} \mu_{V}^{2}\left(1-R_{0}\right) .
\end{array}\right\}
$$

From Equation (39), if $Z_{a}^{*}=0$, then we have disease-free equilibrium treated earlier in Equation (26). The solution to the following equation defines the existence of the possible endemic equilibrium.

$$
\Phi_{2} Z_{a}^{* 2}+\Phi_{1} Z_{a}^{*}+\Phi_{0}=0
$$

The two roots of the quadratic Equation (42) is given by;

$$
Z_{a}^{*}=\frac{-\Phi_{1} \pm \sqrt{\Phi_{1}^{2}-4 \Phi_{2} \Phi_{0}}}{2 \Phi_{0}}
$$

Consequently, depending on the signs of $\Phi_{2}, \Phi_{1}$ and $\Phi_{0}$ the model (1) may have unique, two or no positive roots. We now analyze the three scenarios as follows.

Case 1:

If $R_{0}=1$ then $\Phi_{0}=0, \Phi_{1}<0, \Phi_{2}>0$,

$$
\begin{aligned}
& \Phi_{2} Z_{a}^{* 2}-\Phi_{1} Z_{a}^{*}=0, \\
& Z_{a}^{*}\left(\Phi_{2} Z_{a}^{*}-\Phi_{1}\right)=0
\end{aligned}
$$

Therefore,

$$
Z_{a 1}^{*}=0, Z_{a 2}^{*}=\frac{\Phi_{1}}{\Phi_{2}}
$$


$Z_{a 1}^{*}=0$ represents the disease free case and $Z_{a 2}^{*}=\frac{\Phi_{1}}{\Phi_{2}}$ represent a unique positive equilibrium point. This is the critical equilibrium point.

Case 2:

If $R_{0}>1$ then $\Phi_{0}>0, \Phi_{1}<0, \Phi_{2}>0$ and using the signs rule Descartes, the sign of the coefficients of the quadratic Equation (39) changes once. So there is a unique positive equilibrium point, $Z_{a 1}^{*}>0$. Consequently, there exist at least one endemic equilibrium point.

Case 3:

If $R_{0}<1$ then $\Phi_{0}>0, \Phi_{1}<0$ and using the signs rule by Descartes, the sign of the coefficients of the quadratic Equation (31) changes twice. So there are two unique positive equilibria point. Consequently, $Z_{a}^{*}$ has two positive endemic turning points, implying that at $R_{0}<1$ there is a possibility for the model to exhibit backward bifurcation. So the existence of the threshold $R_{c}$ is assumed in the result.

\subsection{Bifurcation Analysis of the Endemic Equilibria}

Backward bifurcation plays a fundamental role in controlling and eradicating diseases. Backward bifurcation occurs in models that have multiple equilibria when $R_{0}<1$. Consequently, having $R_{0}<1$ is important but not a sufficient indicator for the control and elimination of the infection [21]. Therefore, there is need to reduce the basic reproductive to avoid endemic states and in turn guarantee viral elimination [22]. Various researchers [23], [24] have established that HIV dynamics models exhibit backward bifurcation phenomenon where the stable virions-free equilibrium co-exist with an endemic equilibrium, for $R_{0}<1$. This section focuses on bifurcations of the model in order to analyze the stability of the endemic equilibrium point. In many epidemic models, the virions-free equilibrium loses the stability when $R_{0}>1$, which results in a bifurcation. From the model (1) we have critical $R_{0}$ denoted by $R_{c}$ as;

$$
R_{c}=\frac{\beta \lambda_{T}\left(\mu_{\mathrm{Za}} \mu_{I}+\alpha \lambda_{\mathrm{Z}}\right)}{\mu_{\mathrm{Za}} \mu_{I}\left(\mu_{\mathrm{Z}} \mu_{I}-\beta \lambda_{T}\right)}
$$

If $R_{c}>1$ in Equation (46) then we have a forward bifurcation and if $R_{c}<1$ then the model exhibit backward bifurcation. It is important to note that existence of a backward bifurcation with endemic equilibrium when $R_{c}<1$ is very important in epidemiological applications. Notably, it has very important consequences in the strategies and control policies designed for HIV viral eradication. From the epidemiological point of view reducing $R_{0}$ below unity is no longer a guarantee that the HIV virions will be eliminated completely or reduced to non-detectable level. In addition, this affects HIV virus control since the disease progresses even when $R_{0}<1$. Furthermore, existence of backward bifurcation may result to a model that is globally unstable. From Equation (46) backward bifurcation is only possible if the rate $\mu_{I}$ at which the infected CD4 $4^{+}$ T-cells dies increases. From model (1) the infected cells may either die naturally 
or they can be destroyed and killed by the activated $\mathrm{CD}^{+} \mathrm{T}$-cells. Another parameter of interest as far as backward bifurcation is concerned is the $\beta$, the rate at which the $\mathrm{CD}^{+}$T-cells are activated. Reducing $\beta$ would lead to backward bifurcation. Biologically, bi-stability may lead to unexpected adverse consequences for ARTs and backward bifurcation may provide an explanation for several phenomena observed clinically among HIV patients.

\section{Epidemiological Implication of Backward Bifurcation}

It is paramount to carry out a deep discussion under epidemiological point of view. From the results it is evident that the bifurcation depends mainly on immunity of the infected person and Treatment, that is, efficacy of the ARTs. Use of ARTs as a way of managing an HIV persons may help in reducing the transmission rate. However, this may only be possible if the person adhere to the drugs. In the model the transmission rate is presented by $\chi$. For the immunity of the infected person it is important to analyze the role played by the CD8 ${ }^{+}$ T-cells. From (46) it can be seen clearly the immune cells plays a very vital role. Therefore, it is fundamental, for HIV eradication, to find ways in which the immunity of the infected person may be boosted. This may be done through proper diet or through use of prescribed medication. Thus it is very important to education people living with HIV/AIDS (PLWHAs) on proper nutrition and the availability on the drugs to boost the immunity.

From the point of HIV virions eradication public policy makers must work to ensure information education material (IEC) are available in all public places. They must also ensure that the drugs are accessible and available. This may play a major role in ensuring that the backward bifurcation scenario are avoided.

In summary if the backward bifurcation cannot be avoided, public policy makers have to particularly be careful since having $R_{0}<1$ does not guarantee that the viral load may get to non-detectable level, the disease might eventually progress to AIDS. However, from the numerical values used in model (1) results to a forward bifurcation as shown in the Figure 4 From an epidemiological point of view, forward bifurcations means that when $R_{0}<1$ small perturbations from $E_{0}$ are unable to generate an endemic disease.in addition, when $R_{0}>1$, such small perturbations move the system (1) away from VFE the epidemic outbreak takes place and the disease might stabilize in an endemic state.

Remark 2. The existence of a backward bifurcation shows that even if $R_{0}<1$ by some control measures, HIV may still persist. The control of HIV becomes more difficult.

\subsection{Global Stability of the Virions-Free Equilibrium}

Using the approach of [25] we investigate the global stability of the virions-free equilibrium for the model (1). Using this approach we list two conditions that if met will guarantee the global asymptotic stability of the virions-free equilibrium.

Theorem 4. Suppose we can express model(1) as; 


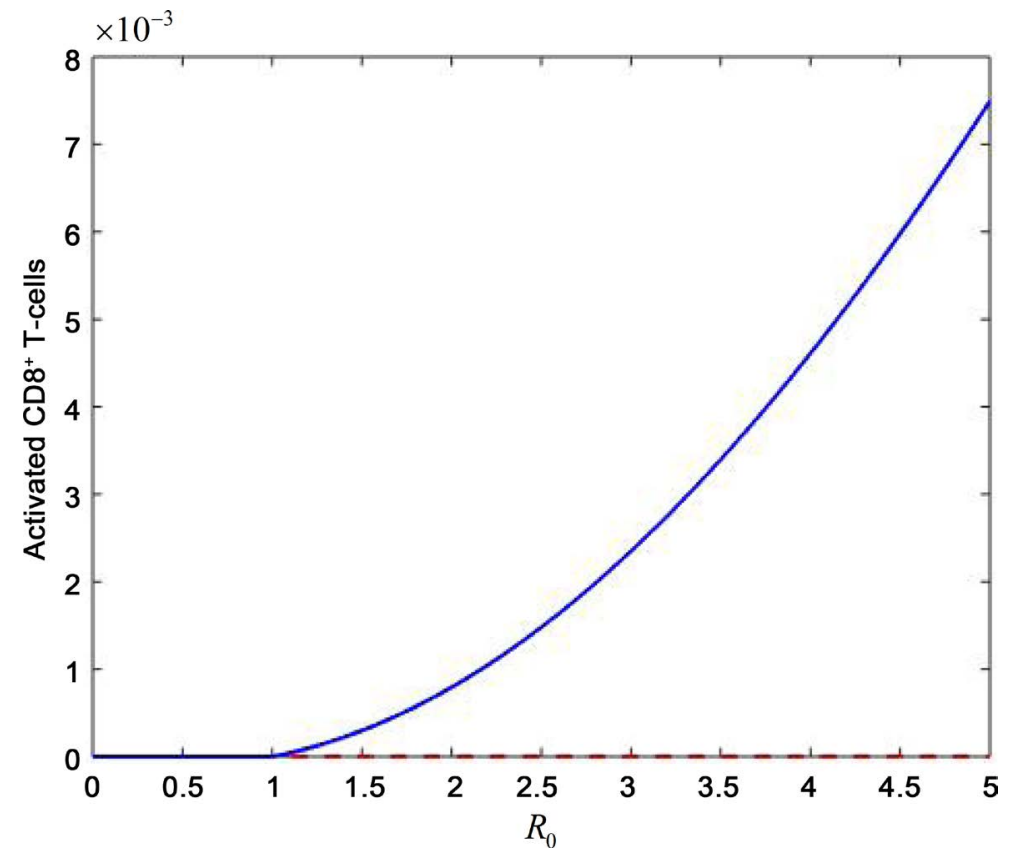

Figure 4. Forward bifurcation (the blue lines denote stability while the red line denote instability).

$$
\begin{aligned}
\frac{\mathrm{d} X}{\mathrm{~d} t} & =H(X, W) \\
\frac{\mathrm{d} Z}{\mathrm{~d} t} & =G(X, W)
\end{aligned}
$$

such that,

$$
G(X, 0)=0
$$

where the column vector components of $X \in R^{M}$ denote the uninfected population and the components of $W \in R^{n}$ denote the infected population. Let $E_{0}=\left(X^{*}, 0\right)$ be the virions-free equilibrium for the system.

Then $E_{0}=\left(X^{*}, 0\right)$ is globally asymptotically stable if and only if:

1) The $R_{0}<1$, that is, locally asymptotically stable.

2) $\frac{\mathrm{d} X}{\mathrm{~d} t}=H(X, 0), X^{*}$ is globally asymptotically stable.

3) $G(X, W)=P G-\hat{G}(X, W), \hat{G}(X, W) \geq 0$ for $(X, Z) \in \Omega_{H}$.

where $P=D_{W} G\left(X^{*}, 0\right)$ represents an M-matrix (the off diagonal elements of $\mathrm{P}$ are non negative) and $\Omega_{H}$ is the feasible reqion for the model.

If model (1) satisfies the conditions mentioned above then the fixed point $E_{0}=\left(X^{*}, 0\right)$ is a globally asymptotic stable equilibrium of model system (1) provided that $R_{0}<R_{c}$. For model (1) the result is stated and proved in Theorem 5 .

Theorem 5. The virions-free equilibrium point $E_{0}=\left(X^{*}, 0\right)$ is a globally asymptotically stable equilibrium of system (1) provided that $R_{0}<R_{c}$ and the conditions (2) and (3) of Theorem 4 are satisfied.

Proof. From the system (1) we let $X=\left(T, Z, Z_{a}\right)$ and $W=(I, V)$, then we 
have;

$$
\begin{gathered}
H(X, 0)=\left(\begin{array}{c}
\lambda_{T}-\mu_{T} T \\
\lambda_{Z}-\mu_{Z} \\
-\mu_{Z a} Z_{a}
\end{array}\right) \\
G(X, W)=P G-\hat{G}(X, W)
\end{gathered}
$$

where

$$
P=\left(\begin{array}{cc}
-\mu_{I} & \chi \frac{\lambda_{T}}{\mu_{T}} \\
\varepsilon_{V} \mu_{I} & -\mu_{V}
\end{array}\right)
$$

and

$$
\hat{G}=\left(\begin{array}{cc}
\alpha Z_{a} I & 0 \\
0 & 0
\end{array}\right)
$$

Since $\alpha Z_{a} I \geq 0$ then, $\hat{G}(X, W) \geq 0$. In addition, the matrix $P$ is an M-Matrix since all its off-diagonal elements are non-negative. This therefore, proves the global stability of the virions-free Equilibrium $\left(E_{0}\right)$. That is, $X^{*}=\left(\frac{\lambda_{T}}{\mu_{T}}, 0,0, \frac{\lambda_{Z}}{\mu_{Z}}, 0\right)$ is globally asymptotic stable equilibrium solution of $\frac{\mathrm{d} X}{\mathrm{~d} t}=H(X, 0)$. Consequently, by Theorem 5 , the disease free equilibrium of the model (1) is globally asymptomatically stable.

Theorem 5 implies that when $R_{0}<R_{c}$ a small influx of free HIV virions into the body cells, will not lead to AIDS. The subsequent numbers of those infected cells will be less than that of their predecessors and eventually the disease maybe reduced to non-detectable level.

\section{Numerical Analysis}

In order to observe the variables on the HIV model given in Equation (1) over a period of time, the study applied Matlab programming language. The initial values of the model were set as; $T_{0}=1000, I_{0}=10, V_{0}=1, Z_{0}=500$, $Z_{a 0}=10$. This section is aimed at investigating numerically the behaviour of each compartment on the onset of infection without any medical treatment. The values for the parameter are described in Table 3.

\section{Discussion}

Figure 5 shows that at initial infection stage the level of the susceptible CD4 $4^{+}$ T-cells reduces for the first three months and later the body immunity stabilizes and the number of the susceptible $\mathrm{CD} 4^{+} \mathrm{T}$-cells increases. However, it fails to go back to the pre-infection stage. Clinicians have established that the depletion of $\mathrm{CD}^{+}{ }^{+} \mathrm{T}$-cells is a indication of HIV infection. Clinicians have established that the first few weeks after infection the virus is characterized by inflammatory response including extreme flu like symptoms such as swollen nodes, fever, sore 
Table 3. Parameters for in-vivo HIV model.

\begin{tabular}{|c|c|c|c|}
\hline Parameters & Description & Value & Source \\
\hline$\lambda_{T}$ & The recruitment rate of non-infected $\mathrm{CD} 4^{+} \mathrm{T}$-cells produced per unit time & $10 \mathrm{cell} / \mathrm{mm}^{3} /$ day & {$[26]$} \\
\hline$\mu_{T}$ & The rate at which the non-infected $\mathrm{CD} 4^{+} \mathrm{T}$-cells decay & 0.01 day $^{-1}$ & [27] \\
\hline$\chi$ & The rate at which the $\mathrm{CD} 4^{+} \mathrm{T}$-cells are infected by the virus & $\begin{array}{c}0.000024 \mathrm{~mm}^{3} \\
\operatorname{vir}^{-1} \text { day }^{-1}\end{array}$ & [8] \\
\hline$\mu_{I}$ & The death rate of the infected $\mathrm{CD} 4^{+} \mathrm{T}$-cells & 0.5 day $^{-1}$ & [28] \\
\hline$\varepsilon_{V}$ & The rate in which HIV virions are generated from the infected CD $4^{+} \mathrm{T}$-cells & 100 vir. cell ${ }^{-1}$ day $^{-1}$ & {$[2]$} \\
\hline$\mu_{v}$ & The death rate of the infectious virus & 3 day $^{-1}$ & {$[2]$.} \\
\hline$\alpha$ & The rate at which the infected cells are eliminated by the activated $\mathrm{CD} 8^{+} \mathrm{T}$-cells & 0.02 day $^{-1}$ & [9] \\
\hline$\lambda_{z}$ & The rate at which the CD8 ${ }^{+} \mathrm{T}$-cells are produced per unit time & $20 \mathrm{cell} / \mathrm{mm}^{3} /$ day & [9] \\
\hline$\mu_{\mathrm{z}}$ & The death rate of the $\mathrm{CD} 8^{+} \mathrm{T}$-cells & 0.06 day $^{-1}$ & [9] \\
\hline$\beta$ & The rate at which the $\mathrm{CD} 8^{+} \mathrm{T}$-cells are activated by the presence of the virus and the infected $\mathrm{CD} 4^{+} \mathrm{T}$-cells & 0.004 day $^{-1}$ & [9] \\
\hline$\mu_{z_{a}}$ & The rate at which the activated defence cells decay & 0.004 day $^{-1}$ & [9] \\
\hline
\end{tabular}

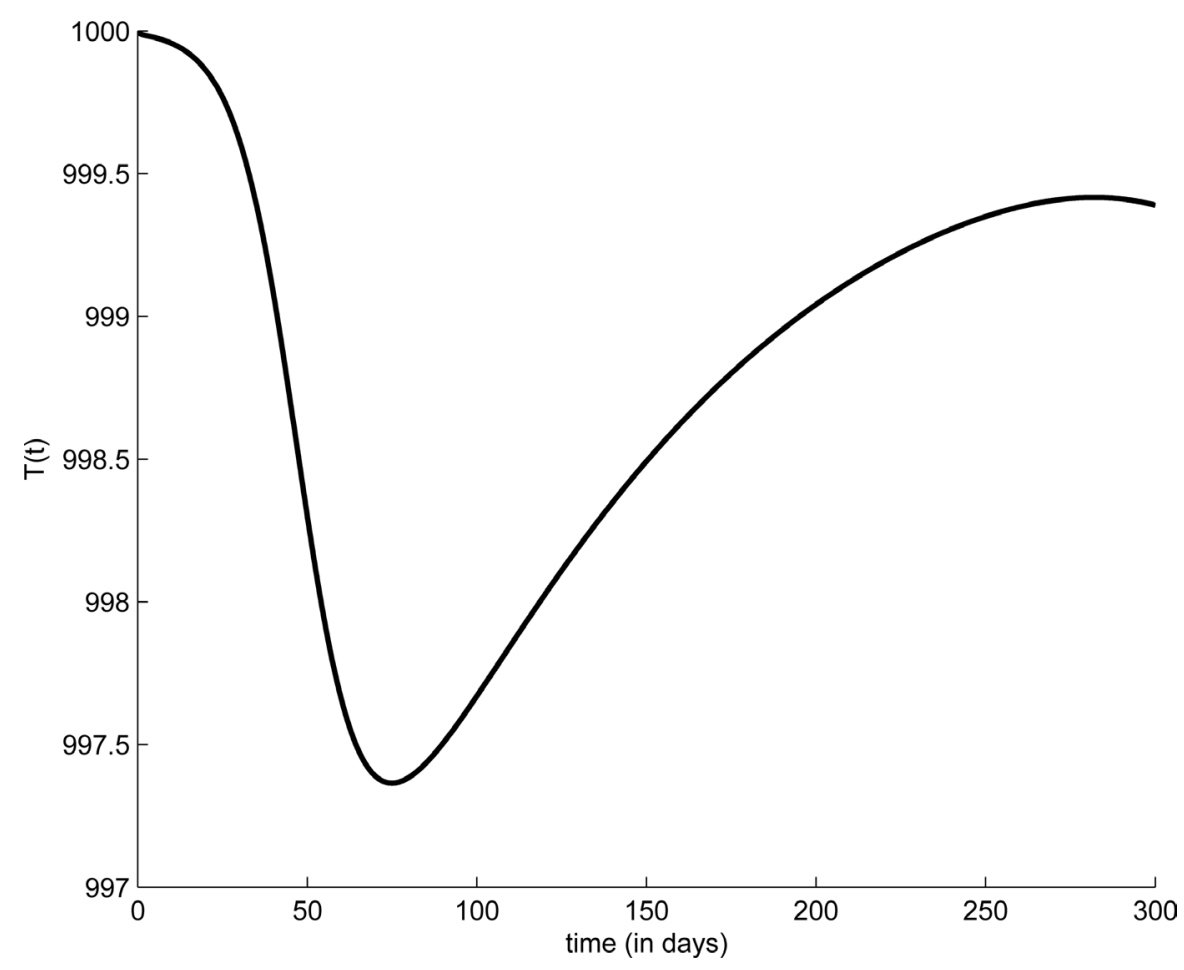

Figure 5. A Figure showing the number of the susceptible $\mathrm{CD} 4^{+} \mathrm{T}$-cells with change.

throat, rashes, muscles and joint pains and headache. This takes place up to the forth week. In this phase the natural immune response changes to "allergy-like" immune response replica of a mild anaphylactic reaction. Due to these changes the viral replication is high, infection of the $\mathrm{CD} 4^{+} \mathrm{T}$-cells is high and the activation of the $\mathrm{CD} 8^{+} \mathrm{T}$-cells and $\mathrm{B}$-lymphocytes rises. As a result, the amount of $\mathrm{CD}^{+}{ }^{+} \mathrm{T}$-cells falls very drastically. Later, due to the immune response, new $\mathrm{CD} 4^{+} \mathrm{T}$-cells are generated rapidly by the thymus to replace the already infected 
ones and hence their level rise again as depicted by the Figure 5 .

In Figure 6, the person has just been infected with HIV virions, the acute infection takes place two to four weeks later. At this time, when the HIV virions infect a few number of the susceptible $\mathrm{CD} 4^{+} \mathrm{T}$-cells, replications take place and new HIV virions are produced. The high number of infectious virions attaches themselves to the membrane of the $\mathrm{CD} 4^{+} \mathrm{T}$-cells infecting them. The cycle continues and more virions are produced hence more $\mathrm{CD} 4^{+} \mathrm{T}$-cells are infected. This explains why the number of the infected $\mathrm{CD}^{+} \mathrm{T}$-cells increases rapidly for the first 2 months as depicted by the Figure 6. Meanwhile at this stage the body is relaying on the natural immune response while waiting for the $\mathrm{CD} 4^{+} \mathrm{T}$-cells Adaptive Immune response. Consequently, the adaptive immune response sets in and kill most of the infected $\mathrm{CD} 4^{+} \mathrm{T}$-cells causing a drastic fall on the number of infected $\mathrm{CD} 4^{+} \mathrm{T}$-cells to almost nil as depicted in the Figure 6. Unfortunately, a few mutants develop. The new mutants start infecting the uninfected $\mathrm{CD} 4^{+}$ $\mathrm{T}$-cells. As a result to this the infected $\mathrm{CD} 4^{+} \mathrm{T}$-cells count rises but at a slower rate. After 300 days the level start to rise again.

Figure 7 shows that at early HIV infection stage the level of the HIV virions reduces to almost zero during. This is the phase in which the virions attaches themselves to the membrane of the $\mathrm{CD} 4^{+} \mathrm{T}$-cells. However, after about three days the infected $\mathrm{CD}^{+} \mathrm{T}$-cells burst releasing infectious HIV virus. This explain why at acute stage of infection, large number of HIV virions are produced in the

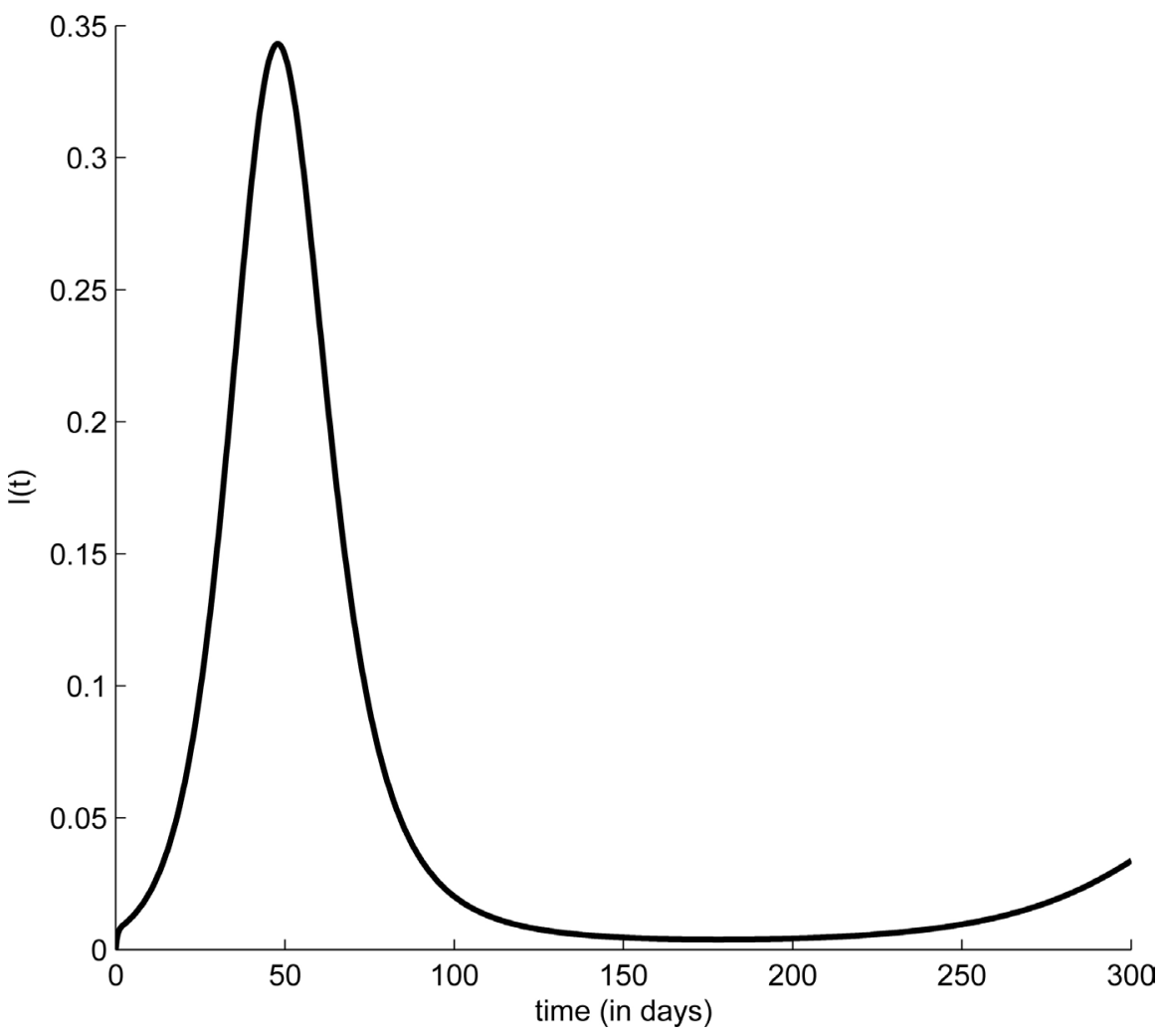

Figure 6. A Figure showing the population of the infected $\mathrm{CD} 4^{+} \mathrm{T}$-cells with respect to time. 


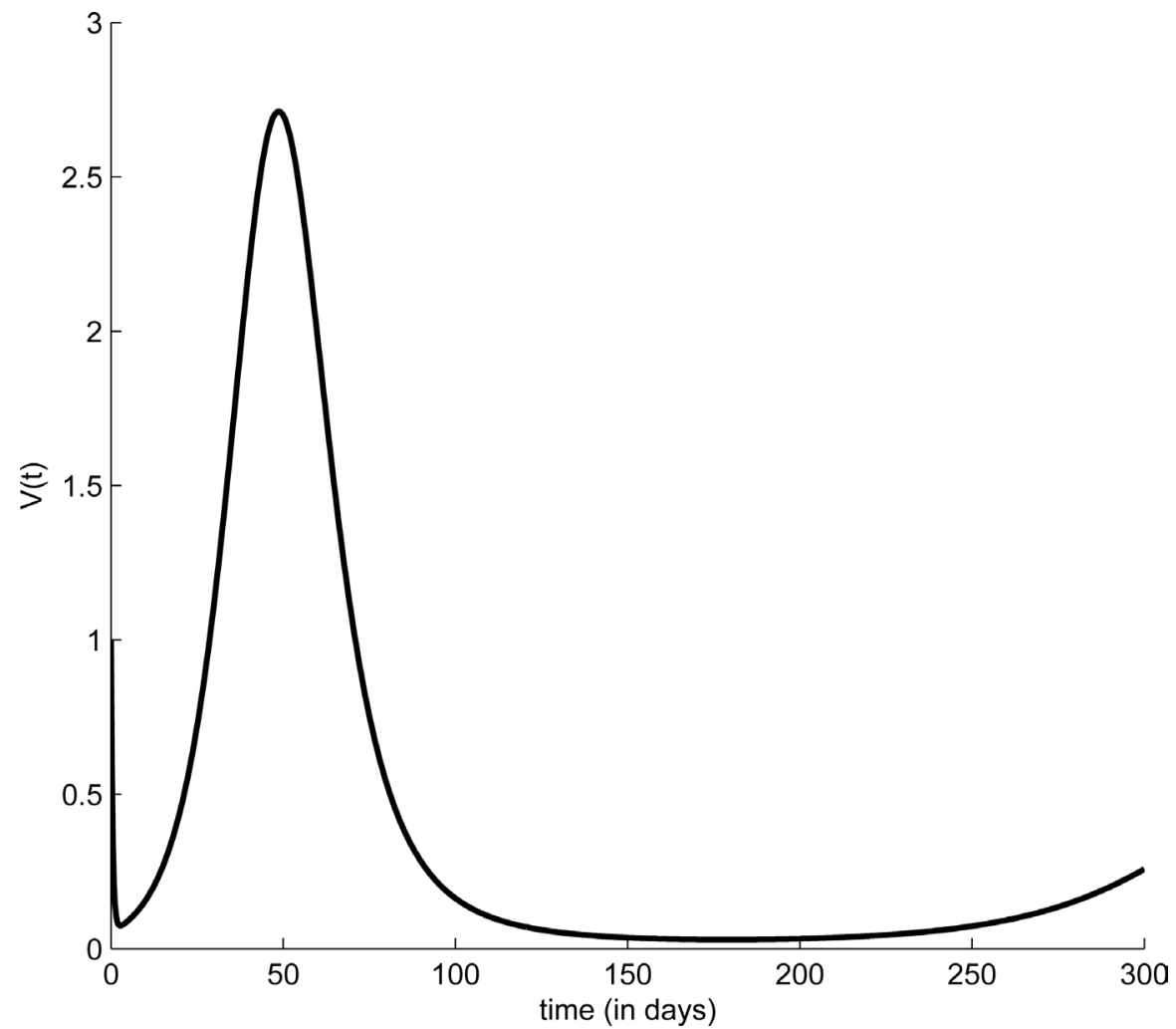

Figure 7. A Figure showing the number of the HIV virions with respect to time.

patients body. With time the HIV virions continue to replicate and infecting more $\mathrm{CD} 4^{+} \mathrm{T}$-cells. This explains the decline on the level of the susceptible $\mathrm{CD} 4^{+}$ T-cells as depicted in Figure 5. However, after the immune response sets in it destroys the infected cells, suppresses viral replication and inhibits more production of the infectious virus since the cells available for infection are decimated. Furthermore, comparing Figure 5 and Figure 7 the number of HIV virions reduces as the number of the susceptible $\mathrm{CD} 4^{+} \mathrm{T}$-cells this is contrarily to the work done by [29]. Their study, which has been criticized by many researches, established that the fall of the viral load was due to a decline in the target cells (CD4 ${ }^{+} \mathrm{T}$-cells), a process called target cell limitation. Consequently, due to the incerase on the number of the infected $\mathrm{CD} 4^{+} \mathrm{T}$-cells, a signal is sent to the $\mathrm{CD} 8^{+} \mathrm{T}$-cell and consequently the cells are activated to kill the infected cells. This helps in reducing the level of the viral load in the body. The number of the $\mathrm{CD} 4^{+} \mathrm{T}$-cells count begins to increase during this point, though it may never return to the pre-infection levels. It may be paramount for the patient to begin ARTs during this stage. The virus level cannot reduce to non-detectable level since it is very difficult to control the HIV virions free in circulation when not attached to the $\mathrm{CD} 4^{+} \mathrm{T}$-cells.

In Figure 8 we monitor the change in the number of $\mathrm{CD}^{+}{ }^{+} \mathrm{T}$-cells during initial infection stage. From Figure 8 the level of $\mathrm{CD} 8^{+} \mathrm{T}$-cells reduces during for the first three months. This may be due to the fact that a big number of the $\mathrm{CD} 8^{+}$ $\mathrm{T}$-cells die within few weeks, leaving a reservoir of $\mathrm{CD} 8^{+}$memory $\mathrm{T}$-cells which 


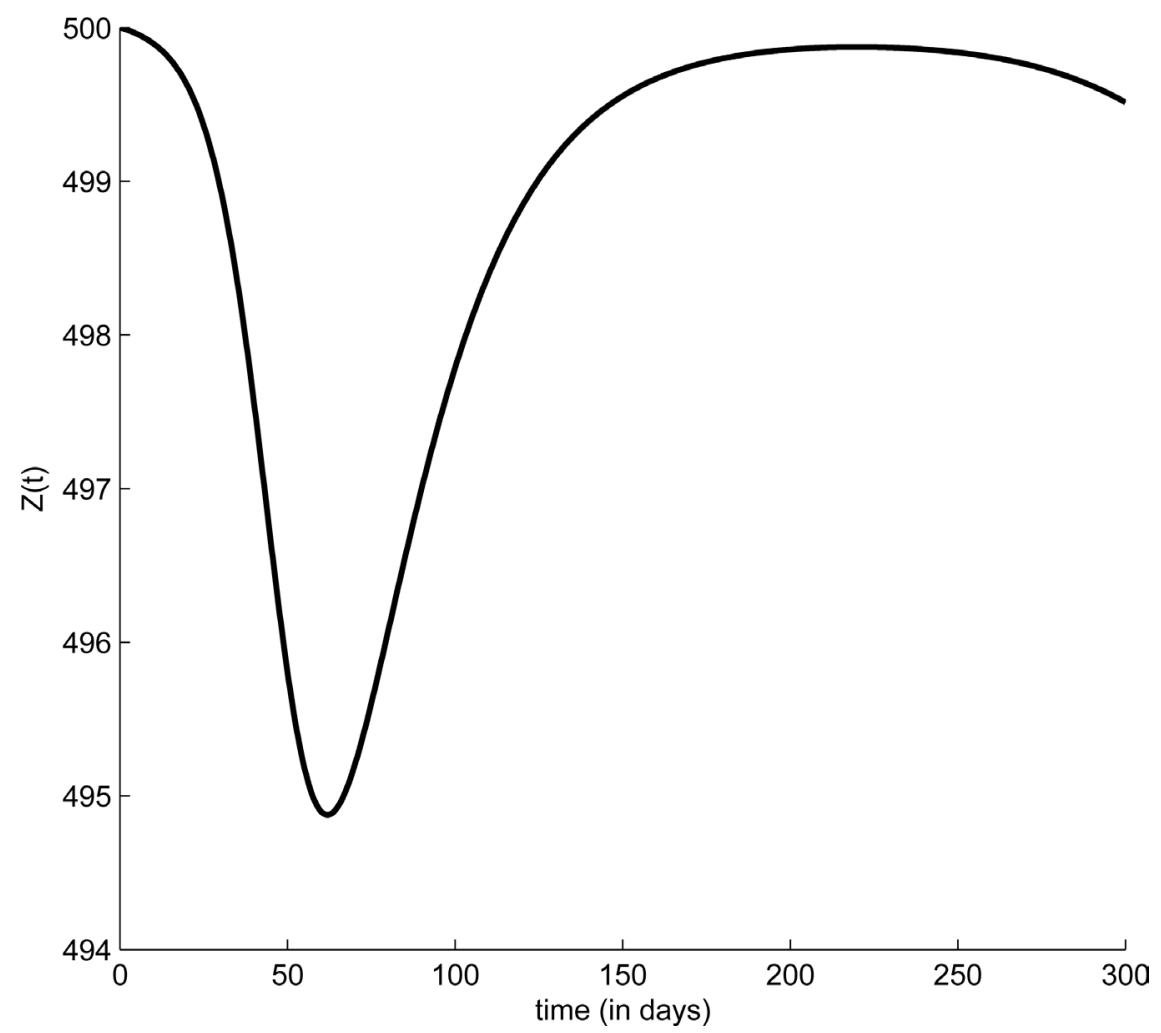

Figure 8. A Figure showing the number of $\mathrm{CD} 8^{+} \mathrm{T}$-cells with respect to time.

are HIV-specific which persist, irrespective of the presence of antigen or CD4 ${ }^{+}$ T-cells. In addition, many of the cells get activated to fight the virus. However, after three months the number increases gradually, this is because of the reduction of the viral load and the infected $\mathrm{CD} 4^{+} \mathrm{T}$-cells.

In Figure 9, we monitor the number of the activated $\mathrm{CD}^{+} \mathrm{T}$-cells. The number of the activated cells rises after the first 3 days. This correspond to the time in which the infected $\mathrm{CD} 4^{+} \mathrm{T}$-cells start to increase. Most of the cells are activated to kill the infected $\mathrm{T}$-cells and consequently control the viral replication. According to [30] $\mathrm{CD}^{+} \mathrm{T}$-cells plays an important role in the initiation and persistence of $\mathrm{CD}^{+} \mathrm{T}$-cells responses. The $\mathrm{CD}^{+} \mathrm{T}$-cell activation can lead to a number of immune responses such as antibody production, activation of phagocytic cells and direct cell killing. Therefore, the best immune response for different types of diseases is implemented by natural mechanism. CD ${ }^{+} \mathrm{T}$-cells have been shown to express $\mathrm{CD}^{+} \mathrm{T}$-cells receptors on their surface after activation through the T-cell receptor, allowing infection by HIV. Some researchers such as [28] suggest this is a mechanism through which $\mathrm{CD}^{+} \mathrm{T}$-cells get destroyed late in infection. From Figure 9 it is evident that during infection most of the $\mathrm{CD}^{+} \mathrm{T}$-cells get activated to fight the virus. This explain the exponential rise.

\section{Conclusion}

In this paper, we have presented an in-vivo HIV dynamics model with inclusion 


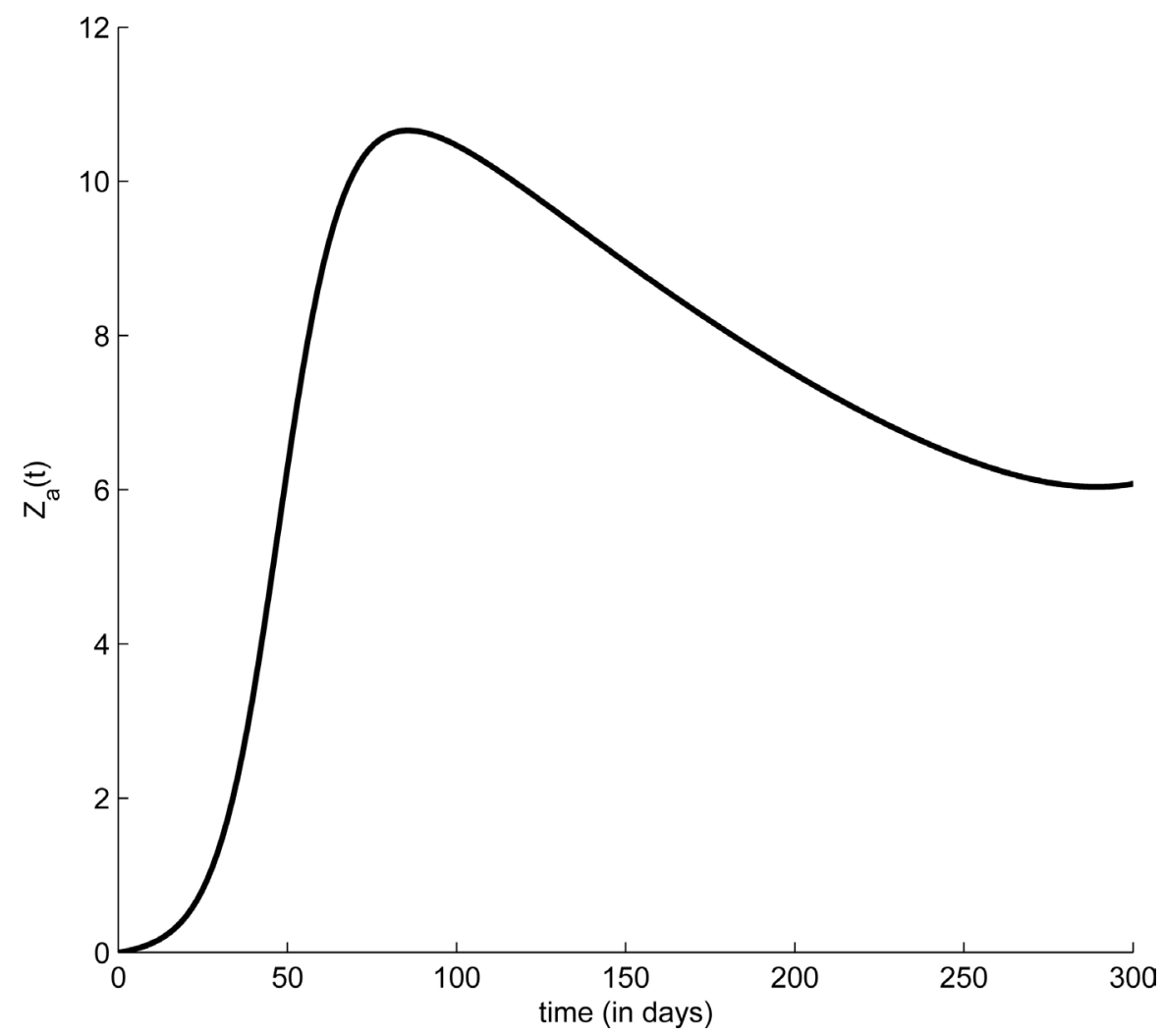

Figure 9. A Figure showing the number of the activated $\mathrm{CD} 8^{+} \mathrm{T}$-cells with respect to time.

of the $\mathrm{CD} 8^{+} \mathrm{T}$-cells. We first showed that the key variables of the model were non-negative and bounded to ensure that it is biologically relevant. We have computed the expression for the basic reproductive number $R_{0}$ and the equilibria of the model. It is evident that the rate of infection greatly influences the basic reproductive number. The mathematical analysis of the model showed the existence of virions-free equilibrium. In addition, the system exhibits backward and trans-critical bifurcation under some restriction on parameters. This shows that having $R_{0}<1$ is not enough to eradicate the HIV-virions to non-detectable level. Numerical analysis were done to give more insight regarding the model. The results clearly show the introduction of HIV virions in the body without the use of ARTs does not mean that the disease is likely to persist in the body. The body have a way of reducing the HIV virions to very low level after three months of infection. This is in agreement with the biological mechanism of the HIV-cells interaction. However, as much as it is so in this study, the parameters were not varied; this means that the behavior might slightly be different between individuals. Furthermore, the simulations for the model have showed the importannce of the $\mathrm{CD} 8^{+} \mathrm{T}$-cells in fighting the HIV virions. At the primary phase of HIV infection, there is an increase in the level viral load and a reduction in the population of the $\mathrm{CD} 4^{+} \mathrm{T}$-cells, which reduces after three months due to the presence of the killer cells. However, as much as this study has only established the role played by the immune cells at the acute 
infection other researches such as [31] has shown that patients who fail to develop HIV/AIDS after 15 years or longer have significantly higher levels of immune cells compared to a normal HIV-infected patients. Therefore, it is fundamental to maintain a high population of the immune cells which in turn will lead to low level of the viral load. In addition, due to the high increase of the virions during the first three months it is important to introduce ARTs to prevent HIV transmission. This will help in the reduction of new infection.

\section{Acknowledgements}

The corresponding author acknowledge the financial support from the DAAD and the National Research Fund from the Government of Kenya.

\section{References}

[1] Greenhalgh, D. and Hay, G. (1997) Mathematical Modelling of the Spread of HIV/ AIDS amongst Injecting Drug Users. Mathematical Medicine and Biology, 14, 11-38. https://doi.org/10.1093/imammb/14.1.11

[2] Mbogo, W.R., Luboobi, L.S. and Odhiambo, J.W. (2013) Stochastic Model for In-Host HIV Dynamics with Therapeutic Intervention. ISRN Biomathematics, 2013, 1-11. https://doi.org/10.1155/2013/103708

[3] United Nations International Children's Emergency Fund, Joint United Nations Programme on HIV and AIDS and World Health Organization (2011) Global HIV/ AIDS Response: Epidemic Update and Health Sector Progress towards Universal Access: Progress Report 2011. World Health Organization, Geneva.

[4] World Health Organization (2010) World Health Statistics 2010. World Health Organization, Geneva.

[5] Joint United Nations Programme on HIV/AIDS (UNAIDS) and Joint United Nations Programme on HIV/AIDS (UNAIDS (2009) Global AIDS Update 2016, Geneva, Switzerland.

[6] Jones, E., Roemer, P., Raghupathi, M. and Pankavich, S. (2013) Analysis and Simulation of the Three-Component Model of HIV Dynamics. SIAM Undergraduate Research Online, 7, 89-106.

[7] Adams, B., Banks, H., Davidian, M., Kwon, H.D., Tran, H., Wynne, S. and Rosenberg, E. (2005) HIV Dynamics: Modeling, Data Analysis, and Optimal Treatment Protocols. Journal of Computational and Applied Mathematics, 184, 10-49. https://doi.org/10.1016/j.cam.2005.02.004

[8] Alizon, S. and Magnus, C. (2012) Modelling the Course of an HIV Infection: Insights from Ecology and Evolution. Viruses, 4, 1984-2013. https://doi.org/10.3390/v4101984

[9] Arruda, E.F., Dias, C.M., De Magalhães, C.V., Pastore, D.H., Thomé, R.C. and Yang, H.M. (2015) An Optimal Control Approach to HIV Immunology. Applied Mathematics, 6, 1115-1130. https://doi.org/10.4236/am.2015.66102

[10] Chandra, P. (2009) Mathematical Modeling of HIV Dynamics: In Vivo. The Indian Mathematical Society Mathematics Student-India, 78, 7-27.

[11] Rivadeneira, P.S., Moog, C.H., Stan, G.B., Costanza, V., Brunet, C., Raffi, F., Ferrfé, V., Mhawej, M.J., Biafore, F., Ouattara, D.A., et al. (2014) Mathematical Modeling of HIV Dynamics after Antiretroviral Therapy Initiation: A Clinical Research Study. AIDS Research and Human Retroviruses, 30, 831-834.

https://doi.org/10.1089/aid.2013.0286 
[12] Wodarz, D. and Nowak, M.A. (2002) Mathematical Models of HIV Pathogenesis and Treatment. BioEssays, 24, 1178-1187. https://doi.org/10.1002/bies.10196

[13] Duffin, R.P. and Tullis, R.H. (2002) Mathematical Models of the Complete Course of HIV Infection and AIDS. Computational and Mathematical Methods in Medicine, 4, 215-221. https://doi.org/10.1080/1027366021000051772

[14] Culshaw, R.V., Ruan, S. and Spiteri, R.J. (2004) Optimal HIV Treatment by Maximising Immune Response. Journal of Mathematical Biology, 48, 545-562. https://doi.org/10.1007/s00285-003-0245-3

[15] Yuan, R., Qi, J., Zhang, Z., Li, S., Gu, Y. and Xia, N. (2016) Anti-CD4: An Alternative Way to Inhibit HIV Infection. HIV \& Retro Virus, 2016, 1-10.

[16] Diekmann, O., Heesterbeek, J.A.P. and Metz, J.A. (1990) On the Definition and the Computation of the Basic Reproduction Ratio in Models for Infectious Diseases in Heterogeneous Populations. Journal of Mathematical Biology, 28, 365-382. https://doi.org/10.1007/BF00178324

[17] Wiah, E. and Mohammed, H. (2014) Nonlinear Dynamics and Chaos in HIV/AIDS Epidemic Model with Treatment. Applied Mathematics, 4, 86-96.

[18] Van den Driessche, P. and Watmough, J. (2002) Reproduction Numbers and Subthreshold Endemic Equilibria for Compartmental Models of Disease Transmission. Mathematical Biosciences, 180, 29-48. https://doi.org/10.1016/S0025-5564(02)00108-6

[19] Hattaf, K. and Yousfi, N. (2012) Optimal Control of a Delayed HIV Infection Model with Immune Response Using an Efficient Numerical Method. ISRN Biomathematics, 2012, 1-7. https://doi.org/10.5402/2012/215124

[20] Hartman, P. (1960) A Lemma in the Theory of Structural Stability of Differential Equations. Proceedings of the American Mathematical Society, 11, 610-620. https://doi.org/10.1090/S0002-9939-1960-0121542-7

[21] Mukandavire, Z., Gumel, A.B., Garira, W. and Tchuenche, J.M. (2009) Mathematical Analysis of a Model for HIV-Malaria Co-Infection. Mathematical Biosciences \& Engineering, 6, 333-362. https://doi.org/10.3934/mbe.2009.6.333

[22] Buonomo, B. and Lacitignola, D. (2011) On the Backward Bifurcation of a Vaccination Model with Nonlinear Incidence. Nonlinear Analysis: Modelling and Control, $16,30-46$.

[23] Gómez-Acevedo, H. and Li, M.Y. (2005) Backward Bifurcation in a Model for HTLV-I Infection of CD4+ T Cells. Bulletin of Mathematical Biology, 67, 101-114. https://doi.org/10.1016/j.bulm.2004.06.004

[24] Sharomi, O., Podder, C., Gumel, A. and Song, B. (2008) Mathematical Analysis of the Transmission Dynamics of HIV/TB Coinfection in the Presence of Treatment. Mathematical Biosciences and Engineering, 5, 145-174. https://doi.org/10.3934/mbe.2008.5.145

[25] Castillo-Chavez, C., Feng, Z. and Huang, W. (2002) On the Computation of Basic Reproductive Number and Its Role on Global Stability. Mathematical Approaches for Emerging and Reemerging Infectious Diseases. An Introduction, 1, 229-254. https://doi.org/10.1007/978-1-4757-3667-0_13

[26] Nowak, M.A., Bonhoeffer, S., Hill, A.M., Boehme, R., Thomas, H.C. and McDade, H. (1996) Viral Dynamics in Hepatitis B Virus Infection. Proceedings of the National Academy of Sciences, 93, 4398-4402. https://doi.org/10.1073/pnas.93.9.4398

[27] Srivastava, P.K. and Chandra, P. (2010) Modeling the Dynamics of HIV and $\mathrm{CD}^{4+} \mathrm{T}$ Cells during Primary Infection. Nonlinear Analysis. Real World Applications, 11, 612-618. https://doi.org/10.1016/j.nonrwa.2008.10.037 
[28] Wodarz, D. and Nowak, M.A. (2000) Immune Responses and Viral Phenotype: Do Replication Rate and Cytopathogenicity Inuence Virus Load? Computational and Mathematical Methods in Medicine, 2, 113-127. https://doi.org/10.1080/10273660008833041

[29] Phillips, R.E., Rowland-Jones, S., Nixon, D.F., Gotch, F.M., Edwards, J.P. and Ogunlesi, A.O. (1997) Human Immunodeficiency Virus Genetic Variation that Can Escape Cytotoxic T cell. US National Library of Medicine, 354, 453-462.

[30] Zhang, S., Zhang, H. and Zhao, J. (2009) The Role of CD4 T Cell Help for CD8 CTL Activation. Biochemical and Biophysical Research Communications, 384, 405-408. https://doi.org/10.1016/j.bbrc.2009.04.134

[31] Wodarz, D. (2001) Helper-Dependent vs. Helper-Independent CTL Responses in HIV Infection: Implications for Drug Therapy and Resistance. Journal of Theoretical Biology, 213, 447-459. https://doi.org/10.1006/jtbi.2001.2426

Submit or recommend next manuscript to SCIRP and we will provide best service for you:

Accepting pre-submission inquiries through Email, Facebook, LinkedIn, Twitter, etc. A wide selection of journals (inclusive of 9 subjects, more than 200 journals) Providing 24-hour high-quality service User-friendly online submission system Fair and swift peer-review system Efficient typesetting and proofreading procedure Display of the result of downloads and visits, as well as the number of cited articles Maximum dissemination of your research work

Submit your manuscript at: http://papersubmission.scirp.org/

Or contact am@scirp.org 